\title{
Modeling Electric Load and Water Consumption Impacts from an Integrated Thermal Energy and Rainwater Storage System for Residential Buildings in Texas
}

\author{
Charles R Upshaw ${ }^{\text {a* }}$, Joshua D Rhodes ${ }^{\text {a, b }}$, Michael E Webber ${ }^{\text {a, b }}$ \\ a Department of Mechanical Engineering, The University of Texas at Austin, Austin, 204 E. Dean Keeton 78712, USA \\ ${ }^{\mathrm{b}}$ Energy Institute, The University of Texas at Austin, Austin, 2304 Whitis Ave, 78712, USA \\ * Corresponding author. Email: crupshaw@utexas.edu; Tel. 1-512-589-3056
}

\begin{abstract}
The United States' built environment is a significant direct and indirect consumer of energy and water. In Texas, and other parts of the Southern and Western US, air conditioning loads, particularly from residential buildings, contribute significantly to the peak electricity load on the grid, straining transmission. In parallel, water resources in these regions are strained by growing populations and shrinking supplies. One potential method to address both of these issues is to develop integrated thermal energy and auxiliary water (e.g. rainwater, greywater, etc.) storage and management systems that reduce peak load and freshwater consumption. This analysis focuses on a proposed integrated thermal energy and rainwater storage (ITHERST) system that is incorporated into a residential airsource chiller/heat pump with hydronic distribution. This paper describes a step-wise hourly thermodynamic model of the thermal storage system to assess on-peak performance, and a daily volume-balance model of auxiliary water collection and consumption to assess water savings potential. While the model is generalized, this analysis uses a case study of a single family home in Austin, Texas to illustrate its capabilities. The results indicate this ITHERST system could reduce on-peak air conditioning electric power demand by over $75 \%$, with increased overall electric energy consumption of approximately 7-9\%, when optimally sized. Additionally, the modeled rainwater collection reduced municipal water consumption by approximately $53-89 \%$, depending on the system size.
\end{abstract}

Keywords Residential HVAC; Peak Load Shifting; Thermal Storage; Rainwater; Auxiliary Water; ITHERST

\section{Acronyms and Abbreviations}

ITHERST: Integrated thermal energy and rainwater storage

HVAC: Heating, ventilating, and air conditioning

TES: Thermal energy storage

AC: Air conditioning

UT: University of Texas

TUM: Technische Universität München

DX: direct expansion

DOE: US Department of Energy

NREL: National Renewable Energy Laboratory

AHRI: Air conditioning, Heating and Refrigeration Institute

TMY3: Typical Meteorological Year ( $3^{\text {rd }}$ edition)

ARCSA: American Rainwater Catchment Systems Association

ASPE: American Society of Plumbing Engineers

AWWA: American Water Works Association

PLR: Peak Load Reduction

ECC: Energy Consumption Change

cc: Cooling capacity

amb: Ambient (outdoor temperature)

s: Supply

HP: Heat pump

\author{
Load: House cooling load \\ HL: Hydronic loop \\ HLP: Hydronic loop pump \\ FCU: Fan coil unit \\ TSP: Thermal storage loop pump \\ Tot: Total of all system components \\ D: Thermal storage discharge \\ $\mathrm{R}$ : Thermal storage recharge \\ HX: Heat exchanger \\ TS: Thermal storage loop \\ Env: Environmental (heat gain) \\ Conv: Convection \\ FFD: First flush diverter \\ Cap: Capacity (volume) \\ GW: Gray water \\ BW: Black water \\ ppl: People in household \\ bs: Bathroom sink \\ sh: Shower \\ ks: Kitchen sink
}

\section{$1 \quad$ Introduction and Literature Review}

Energy and water resource consumption are underlying many major global stresses, and the combination of climate change and an increasing population might exacerbate them. The built environment (residential and commercial buildings) are major direct and indirect consumers of energy and water. In the United States, approximately $40 \%$ of all primary energy, and about $75 \%$ of all 
electricity produced, are consumed within buildings [1]. While direct water consumption by the built environment is only about $12 \%$ of US water withdrawals, the indirect water footprint of the electricity consumed in the built environment equates to another $34 \%$ of all US water withdrawals, bringing the combined direct and indirect total to just under 50\% [2]. Water is necessary for cooling most thermoelectric power plants that provide electricity to buildings, and electricity is also needed to treat and move water for residential use [3]. This interdependence of energy and water is the source of many potential supply and availability issues, but it might also be the solution to most effectively addressing these issues as well [4].

In many southern states, air conditioning loads drive the overall peak load and wholesale market price of electricity on the electric grids. During the summer in Texas, the cumulative electric demand from residential air conditioners alone can exceed $40 \%$ of the peak load on the electric grid [5]. Because most of these power plants use water for cooling, water scarcity can force them to reduce their power output or turn off entirely [6,7]. If power plants do not have the water available to produce power, price could significantly increase, and/or the supply could become less reliable [6,7].

The Texas population is projected to grow by $80 \%$ in the next 50 years; that growth coupled with projected warming temperatures could lead to both increasing residential water demands and air conditioning loads increasing [8]. This paper proposes addressing both electricity demand and water availability through an integrated approach combining active peak load reduction and significant water savings, with a focus on single-family residential housing, which consists of over 5.7 million units out of 8.5 million total housing units in Texas [9].

There are many technologies available to address water scarcity and electric load challenges, including water efficiency and electricity efficiency measures such as low flow toilets and more efficient air conditioners. While these reduce instantaneous demand, they cannot eliminate consumption (in the case of water) or on-peak demand (in the case of cooling load).

Active water source replacement, such as rainwater harvesting, can significantly reduce or eliminate residential demand for municipal water [10-13]. There has been much research into the water savings capacity of such systems in different configurations, and in different climates around the world [1423]. Additionally, research in the United States has shown that rainwater collection and greywater reuse could potentially save energy on the utility side by reducing energy spent pumping and treating water and wastewater [24].

There are also many strategies available to manage residential building cooling load, including: demand response and centralized control, building pre-cooling and passive thermal storage materials, and active thermal energy storage (TES) systems. Demand response is the temporary interruption (turning off) of an electric load to reduce demand, and there are also similar centralized control strategies that adjust thermostat set-points to delay the rate of air conditioner power cycling [25-27]. Building pre-cooling and other passive thermal storage concepts shift cooling load off-peak by cooling the thermal mass present in the building at off-peak times, and then let the buildings' natural thermal inertia maintain thermal comfort [27-29]. Thermally active, or homeostatic, building concepts actively manage energy flowing in and out of the thermal mass of the building via low energy hydronic systems [30-32]. Active thermal energy storage (TES) - the focus of this paper-is a method of reducing peak electricity load for AC systems by coupling the system with a thermal mass, usually a tank of water or ice, but could also be a phase change material (PCM) [33-37]. This mass is pre-cooled off-peak so that it can be used on-peak to reduce (or replace) the compressor portion of the AC system by supplementing (or fully meeting) the cooling load by warming the pre-cooled water or melting the ice or PCM [33-37].

TES and rainwater harvesting systems usually have higher upfront costs than conventional systems that do not have on-site storage. However, they recoup costs over time by reducing utility bills (electricity, in the case of TES, and municipal water, in the case of rainwater harvesting). However, these technologies have traditionally been limited to larger-scale applications (in the case of TES) for 
the commercial and industrial sectors and/or remote or water-scarce locations (in the case of rainwater harvesting for potable use). Because TES and rainwater harvesting systems traditionally benefit from economies of scale, these technologies generally have yet to be adopted en masse at the residential household level in the continental US [14, 16, 17, 19, 20, 23, 24, 38-40].

One way to potentially improve the economic viability of both rainwater harvesting and thermal energy storage is to integrate the two systems such that they share components. The proposed combined system concept, referred to herein as ITHERST (Integrated Thermal Energy and Rainwater Storage), could potentially increase the economic viability of both systems beyond that of two separate systems. The hypothesis is that the combined value of on-peak electricity demand reduction and water savings from an ITHERST system will exceed the potential energy penalty and associated equipment costs, especially by avoiding redundant components such as the storage tanks, piping, and other devices.

While rainwater collection and thermal storage are mature technologies with well-established methods, there has been limited study of integrated thermal/water storage systems for residential buildings. A previous literature review, performed as part of prior work by the authors on a condenser-side version of the ITHERST system, provides a more in-depth summary on much of the other prior research [41,42]. As noted in those papers, the field of prior research on this particular topic is limited. To summarize that literature review, there have been analyses of similar integrated rainwater/thermal storage concepts, such as work by Gan et al. using rainwater cisterns for ground source heat pump enhancement [43] or by Kalz et al. as a heat sink for a thermo-active building [30]. Both of theses systems primarily focused on heating of the building, and both relied on a passive recharging of the thermal store through environmental heat exchange [30, 43]. Ni et al. and Liu et al. looked at the possibilities of using a reversible heat pump in conjunction with grey water for waste heat recovery and condenser cooling for energy savings purposes, rather than summer peak load reduction specifically $[44,45]$. In all of these papers, the primary (or exclusive) goal is energy savings; existing literature does not assess the potential municipal water savings of incorporating rainwater harvesting for potable consumption as part of a thermal storage system.

There has been also significant research into thermal storage using various forms of groundwater and soil. Kranz and Frick provide an overview of aquifer thermal storage, and analyze the performance of seasonal aquifer thermal storage system used for cooling [46]. Gao et al. analyzed improvement in performance of rainwater-enhanced ground-source heat exchange loops [47]. Novo et al. provide an overview of heat storage in large underground basins, including water tanks and saturated gravel pits [48]. These papers are representative of the work done in the area of water-based ground heat exchange and thermal storage: they are seasonally focused, mostly heating focused, and do not utilize the water for consumption.

The system configuration proposed and assessed in this paper differs from previously proposed system configurations by incorporating the ITHERST indirectly into a hydronic cooling system in a manner similar to stratified chilled water TES. This configuration, as discussed further in Section 2, has the potential to reduce the air conditioning-related peak load significantly more than prior configurations because the heat pump can be turned off entirely during the on-peak hours, leaving only circulation pumps operating. This is a novel configuration and concept, and has yet to be analyzed in the scientific literature. Since this system configuration is unconventional, and the field of integrated water and thermal building systems is limited, a significant knowledge gap exists around the technical and economic feasibility of such systems. This paper attempts to fill this knowledge gap by modeling the technical operation and performance of the system with a case study to assess and illustrate the capabilities.

The idea for the ITHERST configuration proposed in this paper was initially conceived for the University of Texas (UT)/Technische Universität München (TUM) Solar Decathlon 2015 Competition entry, Nexushaus [49, 50]. Solar Decathlon is a nation-wide student competition that, "...challenges collegiate teams to design, build, and operate solar-powered houses that are cost- 
effective, energy-efficient, and attractive." [50]. For the 2015 competition, UT has partnered with TUM to design and build a house addressing the local and regional energy and water constraints through smart design and integrated systems such as the ITHERST concept.

The net effects of the proposed systems from power, energy, water, and economic standpoints are non-obvious, and therefore modeling is necessary to assess their potential impact and value. This paper introduces and describes the conceptual design and operation of the proposed ITHERST system, and discusses two simplified models developed to perform an initial assessment of the system performance for both the thermal storage and potable rainwater collection systems. This model is a necessary first step in eventually answering the questions of economic performance and viability, which will be the focus of future research. This paper concludes with a case study analysis of the proposed systems (using the models developed herein) for the UT/TUM Nexushaus, a small standalone residential house designed for Austin, Texas. This analysis is broken down into two parts: 1) calculate TES system peak load reduction and overall energy consumption compared to operating the system without TES, and 2) estimate the associated municipal water savings from the rainwater collection system with and without thermal storage. These models, and their outputs, will be key components in ultimately analyzing economic viability of this concept.

\section{System Description}

This section discusses the primary components and general operation of the proposed integrated thermal energy and rainwater storage system. The system consists of a rainwater collection system with at least two storage volumes: a primary bulk storage volume, and a secondary volume used for either TES or extra rainwater storage capacity. The two systems function independently of each other, with the primary point of integration being the TES tank volume. Section 2.1 describes the primary components and operation of the hydronic cooling system with indirect rainwater stratified TES. Section 2.2 describes primary components and operation of the auxiliary water system for the house, including potable rainwater collection system, greywater collection and irrigation system, and AC condensate collection.

\subsection{Description of the hydronic system with rainwater thermal storage}

The integrated thermal/water storage system design in this paper was developed specifically for the UT/TUM Solar Decathlon 2015 house as a proof-of-concept, and is meant to provide an advanced design scenario by making use of systems not currently common in residential houses. Cooling and heating are provided by an air-source reversible heat pump (a chiller, in cooling mode) with hydronic distribution to ductless fan coil units, as well as to floor and/or wall radiant heating loops. Hydronic refers to the system using a water (or water/glycol mix) thermal working fluid to deliver heating/cooling from the heat pump to the house, compared to a direct expansion (DX) heat pump system, which uses refrigerant directly as the working fluid. The air-source reversible heat pump contains a vapor-compression heat pump inside-essentially a DX system that cools the hydronic loop working fluid - that uses the outdoor air as a heat sink or source. For example, when providing cooling, the heat pump cools the hydronic working fluid (chiller mode), and rejects that heat to the outdoor air; when the system provides heating, the heat pump absorbs heat from the outdoor air and rejects it to the hydronic working fluid. This type of system is similar to a commercial building's chilled water air conditioning system, except that it provides both heating and cooling via the same hydronic loop (commonly called a 2-pipe system). While the system can provide heating, and the TES could theoretically operate in heating mode as well, this research will only focus on the cooling aspects of the system, since peak-shifting is less of a concern during the winter in Texas. However, this same modelling approach could be applied for heating systems in cooler climates. Figure 1 contains a schematic representation of the main components in the proposed ITHERST concept using a residential hydronic cooling and heating system with indirect rainwater thermal storage. 


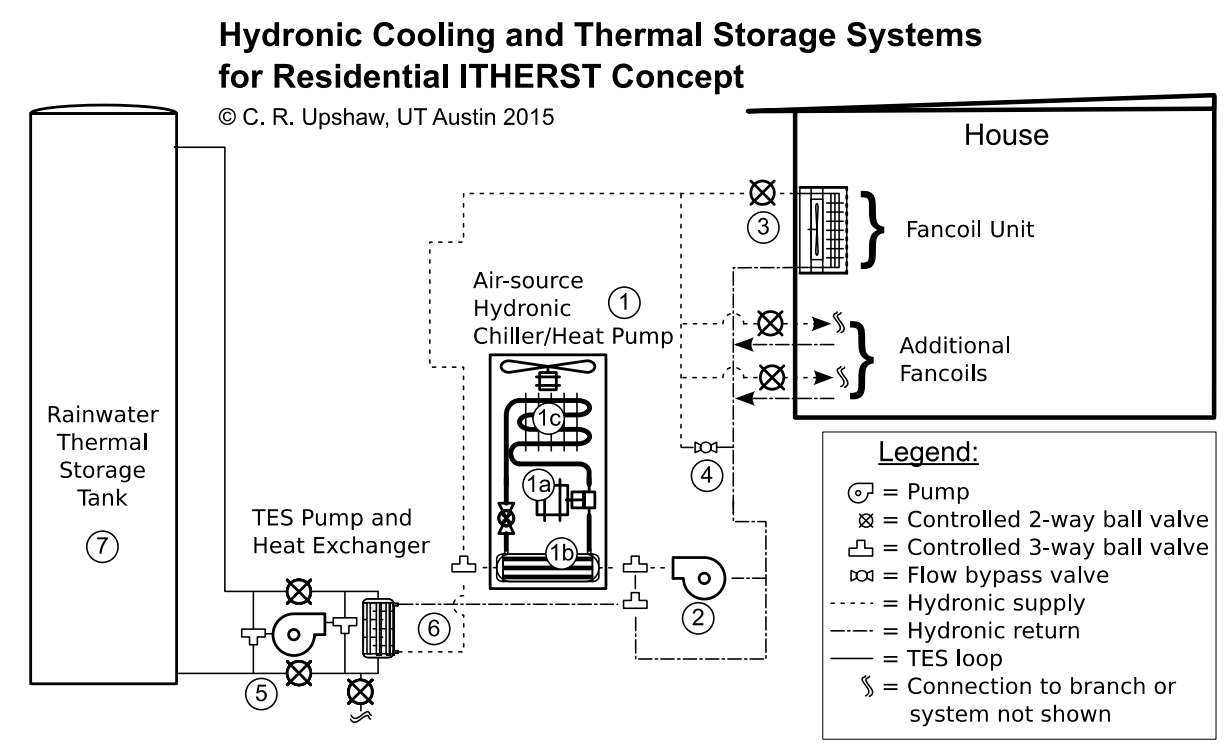

Figure 1: This ITHERST concept uses an air-source reversible heat pump (chiller) with hydronic distribution to fan coil units to provide cooling. An indirect rainwater thermal storage system allows the heat pump to turn off during afternoon hours, reducing on-peak power demand.

This ITHERST system has three modes of operation: 1) Normal Air-Cooled Chiller Mode (the heat pump acting as a chiller to serve house cooling load, TES off), 2) TES Discharge Mode (chiller off, TES serving house load), and 3) TES Recharge Mode (chiller on serving TES and house loads). These three modes occur in four steps (two non-consecutive air-cooled steps) to complete a single daily cycle:

Step 1. Normal Air-Cooled Chiller Mode (post-recharge):

The cooling system operates using its normal air-cooled chiller after the TES has been sufficiently cooled from the day before, and before the on-peak afternoon hours (before $2 \mathrm{pm}$ ). The normal operating mode consists of the air-source chiller (1) cooling the hydronic loop working fluid in the chiller evaporator (1b), and circulating via the circulation pump (2) to the fan coil units (3) as cooling is needed. A bypass valve (4) allows the water to keep circulating at a minimum flow rate when the fan coils are off and/or throttling flow at part load. Heat from the system is rejected to the air from the chiller's condenser heat exchanger (1c). The compressor in the chiller (1a) drives the vapor compression cycle that pumps heat from the low-temperature hydronic working fluid to the outdoor air. The TES pump stays off, and the TES water sits in the tank awaiting use. This mode would be used during the mid-peak times (mid/late morning to early afternoon, late evening), and times when the water/TES system is not available (e.g. tank temperature limit reached).

Step 2. TES Discharge Mode:

During the specified on-peak afternoon hours, the TES discharge mode bypasses the air-source chiller (1), allowing it (including the compressor and condenser fan) to be turned off. The chiller has a high power demand and it is a significant electricity consumer, primarily due to the high power/energy requirements from the compressor. Instead, the circulation pump (2) sends hydronic loop working fluid to the TES heat exchanger (6) before circulating it to the fan coil units (3). The TES pump (5) pulls cold water from the bottom of the tank, passes it through the heat exchanger, and deposits it at the top. The system discharges until the on-peak time period is over, or until the maximum allowable supply water temperature from the tank is reached.

Step 3. Air-Cooled Chiller Mode (post-discharge):

After the peak period has ended, or the TES tank has run out of thermal capacity, the AC system returns to normal air-cooled mode (as in Step 1) for the remainder of the evening (until the signal to recharge the TES is sent). 
Step 4. TES Recharge Mode:

The TES recharge mode operates at night. During the low-demand, cooler, night hours (typically any time between midnight and $6 \mathrm{am}$ ), the hydronic loop pump (2) circulates water through the chiller (1) and to the TES heat exchanger (6) to re-cool the water in the rainwater/TES tank (7), which is being circulated by the rainwater/TES pump (5) through the other side of the heat exchanger (6). The valve arrangement around the rainwater/TES pump allows TES water to be drawn from the top and returned to the bottom during the recharging process, maintaining the tank thermocline. The TES recharge would be performed instead of cycling the chiller off during periods of low demand (i.e. when there is no call for cooling from the house), and the system would switch back to cooling the house via the normal operating mode as needed to meet period demand.

To the best of the authors' knowledge, this integrated thermal/water system design concept is unlike anything currently discussed in the literature or in commercially-available products. While the conceptual design motivation is based on thermodynamic principles, and intuitively should provide some level of peak load reduction and water savings, quantitatively estimating performance requires a detailed thermal/fluid systems model. Therefore, a generalized thermal/fluid systems model was developed to calculate peak electricity load reduction and total energy consumption from a hydronic air conditioning system, both with and without the TES system.

\subsection{Description of the auxiliary water collection systems}

Figure 2 shows the rainwater harvesting and wastewater reuse portion of the proposed ITHERST concept, as part of the overall water system design for the UT/TUM Nexushaus. In this embodiment, the system is configured to capture and treat the rainwater for potable consumption. A non-potable configuration would also be possible provided the water received sufficient treatment to keep the thermal storage heat exchanger from fouling. Additionally, while beyond the scope of this paper, it is possible for a non-potable version of this system to utilize greywater for thermal storage provided sufficient pre-filtration and treatment.

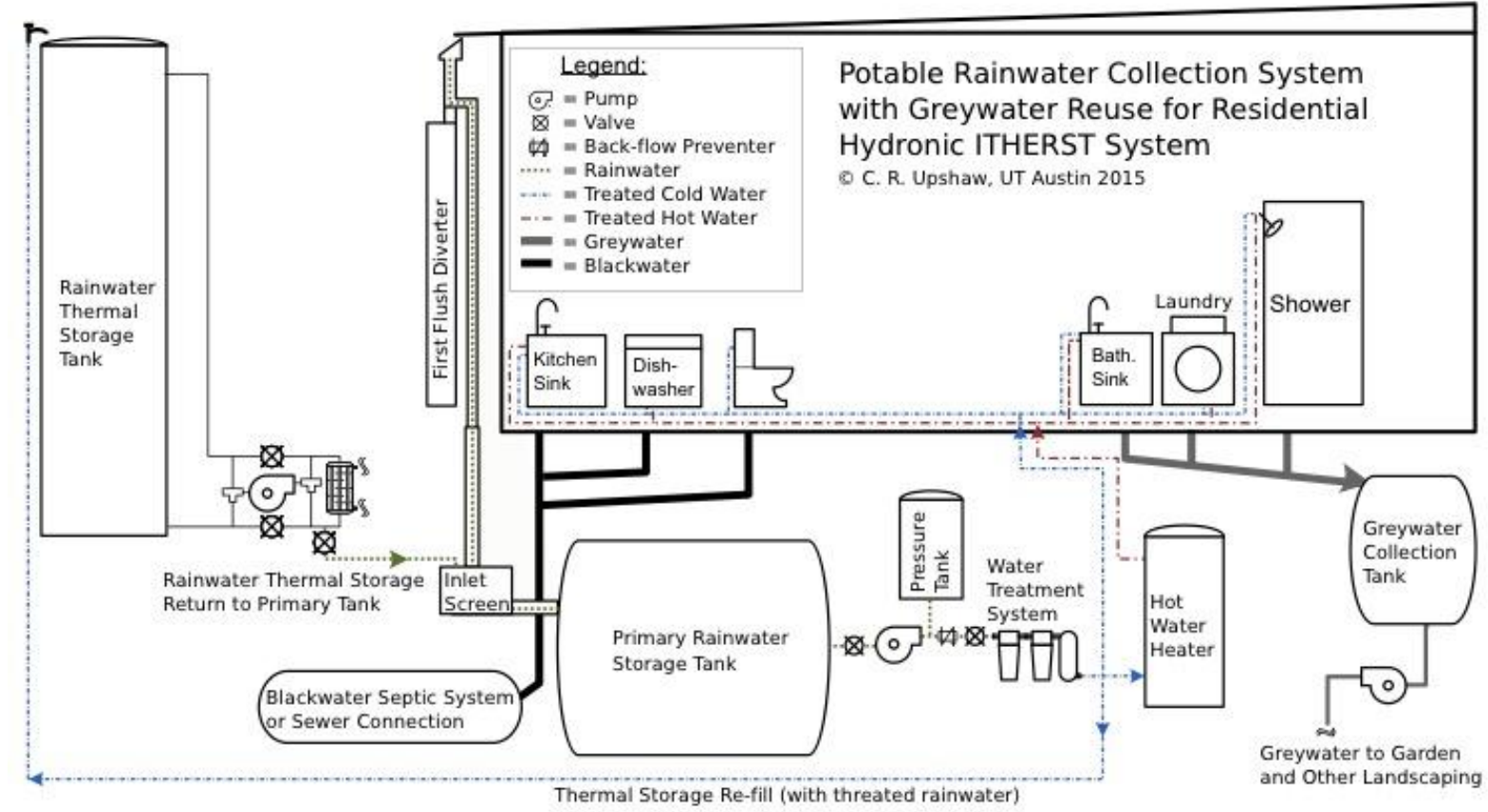

Figure 2: This schematic diagrams the auxiliary water collection and reuse systems for the ITHERST concept analyzed in this paper.

Rainwater is collected off the roof and pre-screened for large debris, and the first-flush diverter diverts the initial rainfall away from the rest of the rainwater collection system. An additional inlet may be used to screen organic matter (such as leaves, bugs, etc.) from the incoming water to minimize contaminants accumulating in the primary collection tank. The primary rainwater collection tank 
catches rainwater, and stores it for eventual consumption in the potable water system, or transfers it to the rainwater thermal storage tank, provided it is not full and/or occupied by thermal storage operation.

When potable water is needed in the house, rainwater is pumped from the primary storage tank through a filtration and treatment system. A pressure tank helps maintain system pressure and keeps the rainwater pump from short cycling. The filtration and treatment system filter and treat water to potable water standards, and then feed into a domestic water system, distributing hot and cold water to each of the end-uses. Water supplied to the kitchen sink, the dishwasher, and the toilets will be collected and conveyed to a blackwater tank (or the sewer). These sources of wastewater typically contain high levels of organic matter (and/or other pollutants), which make it unsafe to re-use without treatment. Water supplied to the bathroom sink, the shower, and the clothes washer will be collected and conveyed to a greywater system. The greywater collection tank accumulates greywater over a span of 24 hours (the maximum the water can be detained without treatment, as per City of Austin plumbing code), after which time it is discharged into a subsurface irrigation system.

The rainwater thermal storage tank is used for the indirect water thermal storage with the hydronic cooling and heating system during the summer months when thermal storage operation is desired over additional rainwater system capacity. In the non-summer months, the rainwater thermal storage tank acts as additional capacity for the rainwater harvesting system.

\section{$3 \quad$ Modeling Methods}

The purpose of this analysis is twofold: 1) to calculate a first-cut approximation of the TES system performance (Peak load reduction and energy consumption) compared to operating the system without TES, and 2) evaluate the associated municipal water savings impact of including these auxiliary water savings systems with and without thermal storage. These outputs will be key to evaluating the economic potential of this concept, as discussed further in section on future work (Section 7). The modeling effort consists of a two-part process:

Part 1:

1) Model the house cooling loads using BEopt (described in the following Section 3.1)

2) Calculate the hydronic cooling system performance with and without TES (Section 3.2)

2a) Model power demand and energy consumption for the heat pump and other hydronic system equipment

2b) Model the TES tank heat transfer and pump power/energy

3) Calculate performance metrics to compare operation scenarios

Part 2:

1) Model the rainwater collection, potable water consumption, and auxiliary wastewater reused for irrigation

2) Calculate performance metrics to assess water municipal water savings potential

These modeling processes are discussed in the following sub-sections. Section 3.1 describes the process of modeling the house thermal loads in BEopt. Section 3.2 describes the governing equations and assumptions used for modeling the heat pump, hydronic system equipment, and the TES. Section 3.3 describes auxiliary water collection, consumption, and reuse modeling in the context of municipal water savings. Section 4 then describes the scope and input values for the Austin case study using these models.

\subsection{Modeling the house thermal load}

BEopt is an energy simulation program developed by the US Department of Energy (DOE) and the National Renewable Energy Laboratory (NREL) [51]. BEopt uses the robust and well-tested EnergyPlus energy simulation engine (Also developed by DOE and NREL) for calculation, but is specifically geared toward modeling residential buildings [51, 52]. User inputs include: house geometry, building insulation values, window area and type, number of bedrooms and bathrooms (sets occupancy level according to Building America modeling guidelines), orientation, appliance usage 
levels, lighting loads, and many other inputs. BEopt then takes these house parameters, along with specified weather data, and simulates the building energy performance for the year. The output taken from the model is the total building cooling load (the amount of thermal energy that is removed from the space) for every hour time interval, which is then fed into the air conditioning and TES system model. Benchmarking BEopt with measured home electricity data has shown that while individual comparisons of energy use can differ significantly (both higher and lower), on average the modeling is reasonably accurate (within approximately 3\%) at estimating electricity use [53].

\subsection{Hydronic air conditioning and TES system model}

The air conditioning and TES system model consists of simplified, semi-empirical and first order theoretical thermodynamic and heat transfer calculations. The primary components modeled are the heat pump, the fan coil(s), the hydronic loop circulation pump, the TES circulation pump, the TES heat exchanger, and the TES tank. The calculations assume steady-state operation over the course of the time interval, operating at the equipment's rated capacity for a fraction of time proportional to the hourly load divided by the hourly system capacity.

\subsubsection{Hydronic heat pump and hydronic loop equipment modeling}

The heat pump cooling capacity and power demand are modeled empirically using a bi-cubic leastsquares curve fit to manufacturer-published operating data. Equation 1 calculates cooling capacity $\left(\dot{Q}_{c c}\right)$ for given ambient outdoor temperature $\left(T_{a m b}\right)$ conditions and supply water temperature $\left(T_{s}\right)$ setpoint.

$\dot{Q}_{c c}=a_{1}+a_{2} T_{a m b}+a_{3} T_{s}+a_{4} T_{a m b} T_{s}+a_{5} T_{a m b}^{2}+a_{6} T_{s}^{2}+a_{7} T_{a m b}^{2} T_{s}+a_{8} T_{a m b} T_{s}^{2}+a_{9} T_{a m b}^{3}+a_{10} T_{s}^{3}$

Similarly, Equation 2 calculates power demand at full capacity $\left(\dot{W}_{H P}\right)$ for given ambient outdoor temperature $\left(T_{a m b}\right)$ conditions and supply water temperature $\left(T_{s}\right)$ setpoint.

$\dot{W}_{H P}=b_{1}+b_{2} T_{a m b}+b_{3} T_{s}+b_{4} T_{a m b} T_{s}+b_{5} T_{a m b}^{2}+b_{6} T_{s}^{2}+b_{7} T_{a m b}^{2} T_{s}+b_{8} T_{a m b} T_{s}^{2}+b_{9} T_{a m b}^{3}+b_{10} T_{s}^{3}$

For this analysis, data for the Daikin ${ }^{\circledR}$ Altherma ${ }^{\circledR}$ air-source hydronic heat pump was used to generate the empirical curves, which are shown in Figure A.1 and Table A.1 [54]. The performance data were obtained from the system's engineering manual [55]. The curve fits match the reported results to within approximately $1 \%$ for any given data point. These data provided by Daikin were gathered in accordance with the European Standard EN 14511 (within 85\% of rated values), and not the US AHRI standard (within $95 \%$ of rated values), so the underlying data for the chiller model is at least within approximately 85\% [56-58]. For this purposes of this initial feasibility analysis, this accuracy is sufficient, but future iterations of system modeling will likely include experimental testing of this and/or other chiller units for more accurate modeling.

The house load, obtained from BEopt model output, represents an idealized fan coil unit in the hydronic system. Instead of calculating the heat transfer between the water and air in the fan coil to obtain $Q_{\text {load }}$, it is assumed that the fan coil is able to absorb this load and rejects it into the hydronic loop. The hydronic loop circulates water (with density $\rho$ and specific heat capacity $C_{P}$ ) at a constant rated flow rate $\left(\dot{V}_{H L P}\right)$ and temperature differential $\left(\Delta T_{H L}\right)$, which sets the hydronic loop system cooling capacity $\left(\dot{Q}_{H L}\right.$ Capacity $)$ shown in Equation 3.

$\dot{Q}_{H L \text { Capacity }}=\dot{V}_{H L P} \rho C_{P} \Delta T_{H L}$

The system (heat pump, fan coils, and hydronic loop pump) operates for a fraction of the hour $\left(f_{o n}\right)$, calculated by dividing the house cooling load $\left(Q_{\text {Load }}\right)$ for time step $t$ by the hydronic loop cooling capacity $\left(\dot{Q}_{H L \text { Capacity }}\right)$, as shown in Equation 4. 
This fraction has units of [hours], and is multiplied by the power demand (a rate value) with units of $[\mathrm{kW}]$ to obtain the total electric energy consumed $\left(W_{H P}\right)$ by the heat pump for the hour in $[\mathrm{kWh}]$. In the event that the house load exceeds the cooling capacity, $f_{\text {on }}$ is set equal to 1 and the excess load is added to the following hour's load.

$W_{H P}=f_{\text {on }} \times \dot{W}_{H P}$

The power demand for the fan coil unit $\left(\dot{W}_{F C U}\right)$ is an assumed constant along with the hydronic loop pump power demand $\left(\dot{W}_{H L P}\right)$, since both are operating at constant flow rates. Hourly electric energy consumption by these devices is calculated by similarly multiplying their rated power by $f_{o n}$ to obtain $W_{F C U}$ and $W_{H L P}$.

The heat pump, hydronic loop pump, and fan coil unit collectively make up the total system operating during normal air-cooled operation. Therefore, the total power demand $\left(\dot{W}_{\text {Tot }}\right)$ and energy consumption $\left(W_{T o t}\right)$ related to household cooling is equal to the sum of the individual power demand and energy consumption for each individual piece of equipment, as shown in Equation 6 and 7.

$\dot{W}_{T o t}=\left(\dot{W}_{H P}+\dot{W}_{F C U}+\dot{W}_{H L P}\right)$
$W_{T o t}=f_{O n} \times\left(\dot{W}_{H P}+\dot{W}_{F C U}+\dot{W}_{H L P}\right)=W_{H P}+W_{F C U}+W_{H L P}$

\subsubsection{TES system pump and heat transfer modeling}

When the system is operating in TES discharge mode, the heat pump is turned off, and instead the TES pump circulates cold water through the TES heat exchanger to cool the hydronic loop water. The TES pump operates at a rated flow rate and power $\left(\dot{W}_{T S P}\right)$, similar to the hydronic loop pump. The TES discharge capacity $\left(Q_{T S_{D}}\right.$ Capacity $)$ is the TES discharge volume $\left(V_{T E S_{D}}\right)$ multiplied by the water density, thermal capacity, and temperature differential $\left(\triangle T_{T E S}\right)$ as shown in Equation 8.

$Q_{T S_{D} \text { Capacity }}=V_{T E S_{D}} \rho C_{P} \Delta T_{T E S}$, where $V_{T E S_{D}}=\min \left\{\left(\dot{V}_{T S P} \Delta t\right)\right.$, or $\left.\left(V_{T E S @ T<T_{D \text { limit }}}\right)\right\}$

The TES discharge volume is the lesser of either the rated flow rate $\left(\dot{V}_{T S P}\right)$ multiplied by the time during one full timestep $(\Delta t)$ or the total volume of water in the tank below the maximum TES supply setpoint temperature $\left(V_{T E S} @ T<T_{D \text { limit }}\right)$. For this analysis, $\Delta T_{T E S}$ is assumed to be equal to $\Delta T_{H L}$, because the flow rates in the TES and hydronic loop systems are chosen to be equivalent, and the heat exchanger is assumed to be adiabatic (e.g. it is well insulated). The heat transfer relationship between the hydronic system and the TES are defined in Equations 9 and 10.

$Q_{T S_{D}}=\min \left\{\left(f_{\text {on }} \times \dot{Q}_{H L \text { Capacity }}\right)\right.$, or $\left.Q_{T S_{D} \text { Capacity }}\right\}$

Equation 9 shows that the heat into the TES tank for a single timestep during discharge $\left(Q_{T S_{D}}\right)$ is equal to the heat removed from (or 'cooling' supplied to) the hydronic loop (to meet $Q_{\text {Load }}$ ), and that these are equal to the minimum of either the rated capacity of the hydronic loop system, multiplied by the runtime fraction, or the remaining capacity of the TES tank. Equation 10 states that the heat removed from the TES tank for a single timestep during recharge $\left(Q_{T S_{R}}\right)$ is equal to the rated capacity of the hydronic loop system, multiplied by the recharge fraction $\left(f_{R}\right)$ of the system. The recharge fraction is defined as the minimum of either $\left(1-f_{o n}\right)$ or the ratio of total volume of water in the tank above the maximum TES recharge setpoint temperature $\left(V_{T E S} @ T>T_{R \text { limit }}\right)$ divided by the rated flow rate $\left(\dot{V}_{T S P}\right)$ multiplied by the time during one full timestep. 
$Q_{T S_{R}}=\left(f_{R}\right) \times \dot{Q}_{H L \text { Capacity }}$, where $f_{R}=\min \left\{\left(1-f_{\text {on }}\right)\right.$, or $\left.\left(1-f_{\text {on }}\right) \times\left(\frac{V_{T E S ~ @ T>T_{R l i m i t}}}{\left(\dot{V}_{T S P} \Delta t\right)}\right)\right\}$

When operating in TES discharge mode, the calculation of the total system power and energy change, as shown in Equations 11 and 12.

$\dot{W}_{T_{T o t_{D}}}=\left(\dot{W}_{T S P}+\dot{W}_{F C U}+\dot{W}_{H L P}\right)$
$W_{T_{T o t_{D}}}=f_{O n} \times\left(\dot{W}_{T S P}+\dot{W}_{F C U}+\dot{W}_{H L P}\right)=W_{T S P}+W_{F C U}+W_{H L P}$

Similarly, when recharging, the system total power $\left(\dot{W}_{T o t_{R}}\right)$ and energy is equal to:

$$
\begin{aligned}
& \dot{W}_{T o t_{R}}=\left(\dot{W}_{T S P}+\dot{W}_{H P}+\dot{W}_{F C U}+\dot{W}_{H L P}\right) \\
& W_{T o t_{R}}=f_{o n} \times\left(\dot{W}_{H P}+\dot{W}_{F C U}+\dot{W}_{H L P}\right)+\left(f_{R}\right) \times\left(\dot{W}_{T S P}+\dot{W}_{H P_{R}}+\dot{W}_{H L P}\right)
\end{aligned}
$$

Since the heat exchanger is treated as adiabatic, and the fluids are both water, and the flow rates are equal, the energy balance between the two reduces down to Equation 15. This equation states that the temperature relationship between the TES side inlet temperature $\left(T_{T S_{i n}}\right)$ is equal to the hydronic side exit temperature plus a constant temperature difference between the two fluids $\left(L M T D_{H X}\right)$; similarly, the TES exit temperature $\left(T_{T S_{\text {out }}}\right)$ is equal to the hydronic side inlet temperature $\left(T_{H L_{i n}}\right)$ plus the same $L M T D_{H X}$. The temperature difference between the two fluids in the heat exchanger $\left(L M T D_{H X}\right)$ is assumed to be a constant based on rated heat exchanger performance at the given flow rates.

$T_{T S_{\text {in }}}=T_{H L_{\text {out }}}+L M T D_{H X}, T_{T S_{\text {out }}}=T_{H L_{\text {in }}}+L M T D_{H X}$

When operating in TES discharge mode, $T_{H L_{\text {out }}}$ equals the TES inlet temperature $T_{T S_{\text {in }}}$ plus the $L M T D_{H X}$, and is the hydronic loop supply temperature during the operation. When operating in TES recharge mode, $T_{H L_{i n}}$ is the hydronic loop supply temperature for recharge operation $\left(T_{H L}\right.$ supply,R$)$, and is a specified input. The recharging hydronic loop supply temperature therefore sets the TES recharging exit temperature $\left(T_{T S_{\text {out }}}\right)$, which is returned to the bottom of the tank.

To keep the model simple and calculation time short for this initial modeling effort, the TES tank was modeled by tracking individual volume segments in a tank temperature/volume matrix. As the model marches through time, it pulls the requisite volume needed for the timestep from the bottom of the tank (in the case of TES discharge mode), and passes it through the TES heat exchanger, where it is heated by the hydronic loop water returning from the fan coil unit, and is returned to the top of the tank. TES recharge mode operates in a similar manner, but in reverse (drawing from the top, discharging to the bottom), where the volume removed is related to the available recharge capacity of the hydronic loop. The volume of water moved and heated/cooled at each timestep $\left(V_{T S P}\right)$ can be solved for by combining equations 8 and 9 , and is equal to the rated TES pump flow rate $\left(\dot{V}_{T S P}\right)$ times the runtime fraction $\left(f_{o n}\right)$.

The model executes these steps during each timestep in the TES discharge and recharge mode. In addition to the energy transferred to/from the system by the heat exchanger, the model also includes a simplified environmental heat gain component. Similar to the thermal stratification logic, the model marches through each temperature/volume segment and calculates the heat gain to that segment using Equation 16.

$T_{T S_{i, \text { new }}}=T_{T S_{i, \text { old }}}+Q_{i, \text { env }} /\left(V_{i} \rho C_{P}\right)$ 
In Equation 16, the new temperature of segment $i\left(T_{T S_{i, n e w}}\right)$ is calculated by dividing the environmental heat gain $\left(Q_{i, e n v}\right)$ by the thermal mass of the volume segment $\left(V_{i} \rho C_{P}\right)$. The environmental heat gain for each segment is calculated using Equation 17,

$Q_{i, e n v}=A_{i} \times\left(\bar{h}_{\text {conv }}^{-1}+R_{\text {tank }}\right)^{-1} \times\left(T_{a m b}-T_{T S_{i, o l d}}\right) \times \Delta t$

where $A_{i}$ is the tank surface area of the segment, $\bar{h}_{\text {conv }}$ is the convection coefficient between the exterior tank surface, and $R_{\text {tank }}$ is the tank insulation thermal resistance. Since $\bar{h}_{\text {conv }}$ and $R_{\text {tank }}$ have units of (thermal) power rather than energy, they are multiplied by the timestep span $\Delta t$ ( 1 hour), in units of [hours], to get total thermal energy.

Equations 16 and 17 simplify each segment into a lumped thermal mass and assume a uniform temperature throughout the layer. Since these are large volumes of water, and the heat flux is small relative to the thermal mass of the segment, the temperatures do not increase significantly relative to the overall temperature difference between the water and the outdoor ambient temperature. Therefore, it is reasonable to approximate the heat flux at a given timestep as constant, rather than modeling the interaction using transient heat transfer equations.

During each timestep in the analysis, the system calculates the environmental heat gain and updates the tank temperatures. The model then checks the hour of day and decides whether it should be operating in normal air-cooled mode, TES discharge mode, or TES recharge mode. If the system is within the TES discharge time period, the system will operate in this mode until either the load is met, or until the supply temperature from the tank exceeds a setpoint limit. Similarly, the system will operate in discharge mode until either the entire excess hydronic loop capacity is used, or until the top of the tank reaches the TES recharge setpoint temperature.

\subsubsection{TES performance evaluation metrics}

The model evaluates the TES system's impact by comparing the total power demand and energy consumption between model runs with and without TES. The model runs the entire analysis without using any TES and compiles the hourly total power demand and energy consumption into two vectors. The model then re-performs the entire analysis with TES and compiles the hourly total power demand and energy consumption into two additional vectors. Two performance metrics, Peak Load Reduction $(P L R)$ and Energy Consumption Change $(E C C)$, are then calculated in both absolute (kW and $\mathrm{kWh})$ and relative percentage (\%) forms. The $P L R_{k W}$ and the $P L R_{\%}$ are defined in Equations 18 and 19.

$$
\begin{aligned}
& P L R_{k W}=\operatorname{average}\left(\dot{W}_{\text {Tot }(\text { No TES })}-\dot{W}_{\text {Tot }(\text { With TES })}\right)_{\text {on peak }} \\
& P L R_{\%}=100 \times \operatorname{average}\left(\left(\dot{W}_{\text {Tot (NoTES) }}-\dot{W}_{\text {Tot }(\text { With TES })}\right) / \dot{W}_{\text {Tot (No TES })}\right) \text { on peak }
\end{aligned}
$$

$P L R_{k W}$ is the difference in total power demand between the two cases, averaged for each hour during the on-peak period. The $P L R_{\%}$ is similar except the difference is normalized by the base case (no TES) total power demand to provide a percentage of peak load reduction.

$E C C_{k W h}$ and the $E C C_{\%}$ are defined in Equations 20 and 21, and are essentially the magnitude and percentage difference in total energy consumption between the TES scenario and the base case.

$$
\begin{aligned}
& E C C_{k W h}=\sum W_{\text {Tot }(\text { With TES })}-\sum W_{\text {Tot (No TES })} \\
& E C C_{\%}=100 \times\left(\sum W_{\text {Tot }(\text { With TES })}-\sum W_{\text {Tot }(\text { No TES })}\right) /\left(W_{\text {Tot (No TES })}\right)
\end{aligned}
$$

Together, the PLR and ECC metrics succinctly capture and summarize the impact of TES on electricity power demand and total electric energy consumption. These two aspects of the system are 
what ultimately will govern whether or not the TES system is a viable means to reduce peak load from residential air conditioning systems.

\subsection{Daily auxiliary water collection and consumption model}

The auxiliary water collection and consumption system is separated into three portions: 1) rainwater collection, 2) potable water consumption, and 3) greywater and air conditioner condensate captured for irrigation. These three segments of the auxiliary water system are represented through a series of volume balances that track the water collected, held, and consumed by the household on a daily basis.

This volume balance method of estimating rainwater collection and consumption is often performed on a monthly basis for rainwater system design $[10,13]$, however using such low fidelity data has been shown to lead to overestimate water collection capacity $[11,14,16,17]$. The daily interval level used in this model improves performance estimation accuracy by increasing fidelity to a level consistent with publicly available water usage data [59,60]. Additionally, the model uses the 'yield after spill' method to bias the volume balance accounting toward conservatively estimating water captured $[15,16,18]$. The basis of this model was adapted from an earlier work by the authors, which looked at the potential for auxiliary water systems to reduce municipal water consumption for outdoor irrigation only [61]. The purpose of this model is to calculate the rainwater captured and consumed, and the amount of outside water that needs to be supplied to make up any shortfall (e.g. from a local municipal source).

\subsubsection{Rainwater collection modeling}

The volume of rainwater conveyed off the roof during the time-step $\left(V_{\text {rain,t }}\right)$ is shown in Equation 22. This function calculates $V_{\text {rain,t }}$ based on product of the depth of precipitation during that time-step $\left(d_{\text {rain }}\right)$, the projected horizontal area of the roof $\left(A_{\text {roof }}\right)$, a volume unit conversion coefficient $\left(C_{v o l ~ c o n v}\right)$, and a roof collection efficiency $\left(\eta_{\text {roof }}\right)$ that relates to what fraction of the water makes its way into the collection system.

$$
V_{\text {rain }, t}=d_{\text {rain }, t} \times A_{\text {roof }} \times C_{\text {vol conv }} \times \eta_{\text {roof }}
$$

Once the water makes its way into the downspout, the model next checks for water diverted during each time step in the first flush diverter $\left(V_{f f d, t}\right)$. The governing logic for this step is,

$$
\begin{aligned}
& \text { if }: V_{\text {rain }, t} \leq\left(V_{f f d, c a p}-V_{f f d, t-1}\right) \text {, } \\
& V_{f f d, t}=V_{f f d, t-1}+V_{\text {rain }, t}, \quad \text { and } V_{\text {collected }, t}=0 \\
& \text { else: } \\
& V_{f f d, t}=V_{f f d, c a p}-V_{f f d, \text { drain }} \quad \text { and } V_{\text {collected }, t}=V_{\text {rain }, t}-\left(V_{f f d, c a p}-V_{f f d, t-1}\right)
\end{aligned}
$$

Where $V_{f f d, c a p}$ is the capacity of the first flush diverter, $V_{f f d, t-1}$ is the volume remaining in the first flush diverter at the end of the previous timestep, and $V_{f f d \text {,drain }}$ is the drainage rate of the first flush diverter (e.g. assuming it has a drip hose attached to it to drain it between periods of rain). Since the first flush diverter is meant to capture the initial volume of rain off the roof during a rainfall event (which is often contaminated with organic matter and dust), it is important that it be drained between periods of rainfall to retain its effectiveness. The collection logic states that if the rainfall onto the roof does not exceed the available capacity of the first flush diverter during that timestep, then no rainfall is collected for consumption; otherwise, all excess rainfall $\left(V_{\text {collected, }}\right)$ makes its way toward the rainwater storage tank volume $\left(V_{\text {storage }}\right)$.

The rainfall captured and 'spilled' (water not captured due to the storage tank being full) is first calculated before consumption from the tank for the timestep. Equation 24 demonstrates the volume of stored water at each timestep $\left(V_{\text {storage, }}\right)$ as the minimum of either the sum of water in the tank 
from the previous timestep $\left(V_{\text {storage }, t-1}\right)$ plus the incoming rainwater $\left(V_{\text {collected, } t}\right)$, or the maximum capacity of the storage tank $\left(V_{\text {storage,max }}\right)$.

$V_{\text {storage }, t}=\min \left\{\left(V_{\text {storage }, t-1}+V_{\text {collected }, t}\right)\right.$, or $\left.V_{\text {storage }, \max }\right\}$

Similarly, volume of water actually captured at each timestep is defined as,

$V_{\text {captured }, t}=\min \left\{V_{\text {collected }, t}\right.$, or $\left.\left(V_{\text {storage, } \max }-V_{\text {storage }, t-1}\right)\right\}$

and the logic governing the amount of water spilled during each timestep $\left(V_{\text {spilled }, t}\right)$ is,

$$
\begin{aligned}
& \text { if }:\left(V_{\text {storage }, t-1}+V_{\text {collected }, t}\right)>V_{\text {storage,max }} \\
& \text { else: } \\
& V_{\text {spilled }, t}=\left(V_{\text {storage }, t-1}+V_{\text {collected }, t}\right)-V_{\text {storage }, \text { max }} \\
& V_{\text {spilled }, t}=0
\end{aligned}
$$

On a seasonal basis, the model can add or remove a portion of the water storage volume from the daily water consumption and collection system for use as thermal storage. The logic governing this action can be described as,

$$
\begin{aligned}
& \text { if: } t<\left(t_{T E S_{\text {start }}}\right) \text { or } \mathrm{t} \geq\left(t_{T E S_{\text {end }}}\right) \\
& V_{\text {storage, } \max }=V_{\text {primary, } \text { max }}+V_{\text {storage, } T E S} \\
& \text { else: } \\
& V_{\text {storage } \max }=V_{\text {primary, } \max } \\
& \text { if }: t==t_{\text {TES }} \text { start } \\
& V_{\text {storage }, t}=\min \left\{\left(V_{\text {storage }, t-1}-V_{\text {storage }, T E S}\right) \text {, or } 0\right\}
\end{aligned}
$$

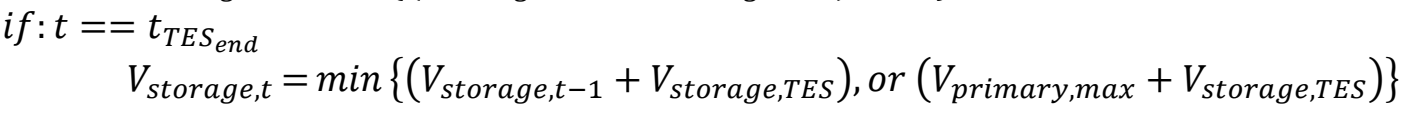

where $t_{T E S_{\text {start }}}$ and $t_{T E S_{\text {end }}}$ are the start and end timesteps for the thermal storage operating mode, $V_{\text {storage,max }}$ is the maximum volume the total system can hold, $V_{\text {primary,max }}$ is the maximum volume the primary storage volume can hold, and $V_{\text {storage,TES }}$ is the volume of the thermal storage system. This logic represents dedicating the thermal storage tank portion of the system purely to thermal storage during the summer months, and then reverting it back to additional storage capacity for the rainwater collection system for the fall, winter, and spring. The intent of this operation mode is to potentially gain some additional utility from the rainwater storage volumes, hopefully without negatively impacting rainwater collection in a significant way. The impact on water savings from doing this seasonal TES operational switch is the focus of the second part of the analysis discussed in Sections 4 and 5.

These values are calculated at every timestep and provide insight into how the system is operating over the span of the analysis period. After performing the rainfall capture balance for the timestep, the model decrements the storage volume by the water consumed during that interval.

\subsubsection{Water consumption and wastewater production modeling}

Water consumption is modeled on the same daily basis as the rainfall collection, and for this analysis only considers the captured rainwater to be consumed inside the home for typical indoor uses. As shown in Equation 28, consumption is divided into two groups: those that produce greywater $\left(V_{g w, t}\right)$, and those that produce blackwater uses $\left(V_{b w, t}\right)$, and the total consumption for each timestep is taken from the storage tank at each timestep. 
$V_{\text {storage }, t}=V_{\text {storage }, t}-V_{g w, t}+V_{b w, t}$

In general, greywater may be captured and re-used for various non-potable tasks; the extent which it can be reused varies by location and governing jurisdiction. Equation 29 defines greywater as the sum of the bathroom sink and shower loads per person, times the number of people $\left(n_{p p l}\right)$, plus the potential laundry water consumption, for the timestep.

$V_{g w, t}=n_{p p l} \times\left(V_{b s} \times f_{b s}+V_{s h} \times f_{s h}\right)+K_{l} \times n_{\text {loads }} \times V_{\text {laundry }}$

Bathroom sink water usage is calculated by multiplying an estimated average volume consumed per use $\left(V_{b s}\right)$ by the estimated average number of uses per day $\left(f_{b s}\right)$; Shower usage is determined with a similar volume per use $\left(V_{s h}\right)$ and frequency of use $\left(f_{s h}\right)$ parameters. Since laundry is often more of a weekly task rather than a daily habit, laundry water usage was confined to a single laundry day of the week $\left(K_{l}=1\right.$ if laundry day, else $\left.K_{l}=0\right)$, where all of the weekly loads $\left(n_{\text {loads }}\right)$ were washed, consuming an average volume of water $\left(V_{\text {laundry }}\right)$ per load. While not the explicit focus of this analysis, the water system for this house was designed to capture and re-use this water for irrigating the landscape. All of $V_{g w, t}$ goes toward irrigation, along with the air conditioner condensate produced during that timestep. While not the focus of this analysis, it can be argued that the re-used wastewater offsets some portion of additional municipal water consumption that might otherwise go toward irrigation.

Blackwater on the other hand, generally cannot be captured or re-used directly due to its contamination by organic matter and human waste. Blackwater consumption is defined as,

$V_{b w, t}=n_{\text {ppl }} \times\left(V_{\text {toilet }} \times f_{\text {toilet }}+V_{k s} \times f_{k s}\right)+K_{d} \times V_{\text {dishes }}$

Where $V_{b w, t}$ is the volume of blackwater produced, $n_{p p l}$ is the number of people in the house, $V_{\text {toilet }}$ is the average volume per toilet use, $f_{\text {toilet }}$ is the average frequency of toilet use per timestep, $V_{k s}$ is the average volume per kitchen sink use, $f_{k s}$ is the average frequency of kitchen sink use per timestep, $K_{d}$ is the integer counter for dishwashing days ( $K_{d}=1$ for even days of week, zero for odd days), and $V_{\text {dishes }}$ is the average volume per load of dishes.

If consumption leaves the storage less than zero for the timestep (i.e. $V_{\text {storage, }}<0$ ), then the amount of municipal water needed to make up the deficit is equal to the negative of the storage volume, and the storage is set to zero (shown in Equation 31).

if: $V_{\text {storage }, t}<0, V_{\text {city }, t}=-\left(V_{\text {storage }, t}\right)$, and $V_{\text {storage }, t}=0$

This logic determines if, and how much, municipal water needs to be obtained should the storage tanks run dry. The inherent goal of the rainwater collection system is to minimize (or eliminate, ideally) $V_{c i t y, t}$, in turn making the house less reliant and less impactful on the local municipal water system and sources.

\subsubsection{Water system performance evaluation metrics}

To assess the performance of the rainwater collection system, this analysis focuses on the metrics of total municipal water consumption, as both a magnitude and fraction of total household consumption $\left(V_{\text {city }}\right.$ and $\left.f_{\text {city }}\right)$, total water captured $\left(V_{\text {captured }}\right)$, and total water spilled $\left(V_{\text {spilled }}\right)$. These values are defined in Equations 32-35.

$V_{\text {city }}=\sum V_{\text {city, }}$ 


$$
\begin{aligned}
& f_{\text {city }}=\left(\sum\left(V_{g w, t}+V_{b w, t}\right)-\sum V_{\text {city }, t}\right) / \sum\left(V_{g w, t}+V_{b w, t}\right) \\
& V_{\text {captured }}=\sum V_{\text {captured }, t} \\
& V_{\text {spilled }}=\sum V_{\text {spilled }, t}
\end{aligned}
$$

By summing these variables over the span of all the timesteps analyzed, the overall effectiveness and water savings value to the homeowner can be assessed for the given set of system design input parameters.

\section{$4 \quad$ Analysis Inputs and Outputs}

The modeled systems, as described, are fairly general, and could be readily adapted to a wide variety of locations and/or operating schemes, for example locations outside of Austin, Texas or systems with significant demand reduction or load shaping needed at other times. However, this analysis focuses specifically on assessing the load shifting and water savings performance of the ITHERST system for the UT/TUM Nexushaus in Austin, Texas, and because Austin is suitable representative of a hot and semi-dry climate in which summer lead load reduction and municipal water savings are appealing. The goals of this analysis were threefold:

1) Assess the hydronic system thermal load shifting performance over a range of TES tank water volumes to determine an optimal TES tank size,

2) Assess the rainwater collection ability of the house over a range of water storage volumes to determine an optimal rainwater collection volume, and

3) Assess the impact on water collection ability of the house when using a portion of the rainwater collection volume for TES (as part of the ITHERST concept)

The systems are evaluated using the performance metrics described in Section 3.2.3 and 3.3.3, which provide insight into the overall value of the system to the homeowner and/or utilities. It is necessary to conduct this analysis over a range of tank volumes to determine the shape and slope of the performance vs. volume curve. Conventional wisdom for both thermal storage and rainwater collection systems has typically been 'bigger is always better,' but this analysis aims to test this hypothesis or to determine if there are diminishing returns (or even a drop-off in performance) at larger volumes.

The inputs to the model are described in Section 4.1, and the resulting outputs are given in Section 4.2.

\subsection{Model inputs}

This analysis was performed to help determine the optimal size of TES tank to use in the Nexushaus HVAC design, as well as adequately size the rainwater collection system for the expected indoor potable water load, and determine the impact of the ITHERST system concept on the effectiveness of the rainwater collection system. The first step in the modelling process was to calculate the cooling load using the BEopt model discussed in Section 3.1. This cooling load dataset was then fed into the TES model to calculate the power demand and energy consumption, both with and without thermal storage. The house design parameters relevant to the TES modeling process are described in Table 1, and the parameters relevant to the rainwater collection and consumption are described in Table 2 .

The TES performance analysis focuses on single-summer modeled performance runs using weather data from a 'Typical Meteorological Year' (TMY3, or the $3^{\text {rd }}$ iteration of the curated TMY dataset), and three prior historical years $(2011,2012$, and 2013) [62, 63]. The TMY3 data represents a statistically 'average' weather year in Austin, based on the past 30 years [62]. Conversely, 2011 was the single hottest year on record in Texas, while 2012 and 2013 were hotter than the TMY3 year, but cooler than 2011 [63]. Weather data from these years were used with BEopt to generate the hourly cooling load for the house over the utility-defined summer season, June $1^{\text {st }}$ through September $30^{\text {th }}$ [64]. For this analysis, the on-peak period was defined as starting at $2 \mathrm{pm}$ and continuing until $8 \mathrm{pm}$, to coincide with the high-priced 'on-peak' afternoon tier defined by Austin Energy [64]. The cooling 
load output from BEopt, and the modeled electricity consumption for the reference case are provided in Section 4.2 and discussed in Section 5.1 to provide context on the size of the house and magnitude of consumption, and how these numbers might scale for a typical Austin house.

Table 1: Modeling parameters used for the TES portion of the analysis were based on the design of the UT/TUM Nexushaus, part of the US DOE Solar Decathlon.

\begin{tabular}{|c|c|c|c|c|}
\hline House/Model Parameter & Value & SI Units & Value & IP Units \\
\hline House Finished Floor Area & 72.8 & {$\left[\mathrm{~m}^{2}\right]$} & 784 & {$\left[f t^{2}\right]$} \\
\hline Roof Insulation (BEopt input) & 6.7 & {$\left[\mathrm{~m}^{2 \circ} \mathrm{C} / \mathrm{W}\right]$} & 38 & {$\left[f t^{2}{ }^{\circ} \mathrm{F} h r / B T U\right]$} \\
\hline Wall Insulation (Beopt input) & 3.5 & {$\left[m^{2 \circ} \mathrm{C} / W\right]$} & 20 & {$\left[f t^{2}{ }^{\circ} \mathrm{F} h r / B T U\right]$} \\
\hline Window Area (Beopt input). & .18 & {$\left[A_{\text {Window }} / A_{\text {Wall }}\right]$} & .18 & {$\left[A_{\text {Window }} / A_{\text {Wall }}\right]$} \\
\hline Hydronic Loop Flow Rate, $\dot{V}_{H L P}$ & 9.46 & [Litres/min] & 2.5 & [ gal/min] \\
\hline Hydronic Loop Deign $\triangle T$ & 6.67 & {$\left[{ }^{\circ} \mathrm{C}\right]$} & 12 & {$\left[{ }^{\circ} \mathrm{F}\right]$} \\
\hline TES Loop Flow Rate, $\dot{V}_{T S P}$ & 9.46 & [Litres/min] & 2.5 & [gal/min] \\
\hline TES Loop $\triangle T$ & 6.67 & {$\left[{ }^{\circ} \mathrm{C}\right]$} & 12 & {$\left[{ }^{\circ} \mathrm{F}\right]$} \\
\hline$T_{\text {HL Supply }}$ & 7.22 & {$\left[{ }^{\circ} \mathrm{C}\right]$} & 45 & {$\left[{ }^{\circ} \mathrm{F}\right]$} \\
\hline$T_{H L \text { Supply, } R}$ & 5 & {$\left[{ }^{\circ} \mathrm{C}\right]$} & 41 & {$\left[{ }^{\circ} \mathrm{F}\right]$} \\
\hline$L M T D_{H X}$ & 1.11 & {$\left[{ }^{\circ} \mathrm{C}\right]$} & 2 & {$\left[{ }^{\circ} \mathrm{F}\right]$} \\
\hline TES Tank Water Volume & $378.5-3785$ & [L] & $100-1000$ & [gal] \\
\hline TES Tank Insulation, $R_{\text {Tank }}$ & 3.5 & {$\left[m^{2 \circ} \mathrm{C} / W\right]$} & 20 & {$\left[f t^{2 \circ} \mathrm{F} h r / B T U\right]$} \\
\hline Tank Convection Coefficient, $\bar{h}_{\text {conv }}$ & 50 & {$\left[\mathrm{~W} / \mathrm{m}^{2}{ }^{\circ} \mathrm{C}\right]$} & 171 & {$\left[B T U / h r f t^{2}{ }^{\circ} F\right]$} \\
\hline$t_{T E S \text { discharge, start }}$ & \multicolumn{4}{|c|}{$14: 00(2 \mathrm{pm})$} \\
\hline$t_{T E S}$ discharge, end & \multicolumn{4}{|c|}{$20: 00(8 p m)$} \\
\hline$t_{T E S \text { recharge, start }}$ & \multicolumn{4}{|c|}{ 00:00 (midnight } \\
\hline$t_{T E S \text { season, start }}$ & \multirow{2}{*}{\multicolumn{4}{|c|}{$\begin{array}{c}\text { 00:00 (midnight), May } 1^{\text {st }} \\
\text { 00:00 (midnight), October } 1^{\text {st }}\end{array}$}} \\
\hline$t_{T E S \text { season, end }}$ & & & & \\
\hline
\end{tabular}

The house roof area was taken from the Nexushaus as the combined roof and deck canopy area, and the first flush volume was a specified function of roof area $\left(2\right.$ gallons per $100 \mathrm{ft}^{2}$, or $0.076 \mathrm{~L}$ per m$~_{2}^{2}$, of roof) as part of the Solar Decathlon competition building code [65]. Roof collection efficiency was based on typical values cited in the ARCSA/ASPE Rainwater Catchment Design and Installation code [13]. The frequencies of use were estimated based on data from the 1999 Residential End Uses of Water Survey by the AWWA [59] and the 2011 California Single Family Water Use Efficiency Study [60], with adjustment based on the Nexushaus design and intended use. Water consumption per event was based on the same combination of study data and customized adjustment to more closely match the water-efficient Nexushaus design scenario. The analysis period used historical daily rainfall data for 2011, 2012, and 2013 [63]. Just as with the TES analysis, the May $1^{\text {st }}-$ October $1^{\text {st }}$ date range was used for the model runs where the thermal storage volume was utilized for TES instead of as storage capacity.

The tank size ranges analyzed in this paper are 100-1,000 gallons $(378.5-3,785 \mathrm{~L})$ for the thermal storage volume, and $500-19,500$ gallons $(1893-73815 \mathrm{~L})$ for the primary rainwater collection volume. These ranges were ultimately chosen after initial exploratory analyses pointed to non-linear trends and asymptotic behavior in the performance outputs. Additionally, since the volume of off-theshelf tanks is discrete (e.g. often manufactured in 100 or 500 gallon increments), the step size was selected to reflect this non-continuous nature. These trends are discussed further in Section 5.1 and 5.2 .

The resulting model outputs for both the thermal storage analysis and the rainwater collection and consumption analysis are discussed in the following section. 
Table 2: The modeling parameters used for the rainwater collection and consumption portion of the analysis were based on the Nexushaus design.

\begin{tabular}{|c|c|c|c|c|}
\hline House/Model Parameter & Value & SI Units & Value & IP Units \\
\hline Horizontal Projected Roof Area & 185.8 & {$\left[m^{2}\right]$} & 2000 & {$\left[f t^{2}\right]$} \\
\hline Roof collection efficiency & 0.85 & - & 0.85 & - \\
\hline First Flush Diverter Capacity & 151 & [Liter] & 40 & [gal] \\
\hline Primary Rainwater Storage Capacity & $1893-73815$ & [Liter] & $500-19500$ & [gal] \\
\hline TES Tank Water Storage Capacity & 1893 & [Liter] & 500 & [gal] \\
\hline Number of People in Household & 3 & [people] & 3 & same \\
\hline Bathroom Sink Consumption per Use & 0.95 & [Liter/use] & 0.25 & [gal/use] \\
\hline Bathroom Sink Use per Person per Day & 6 & [use/person/day)] & 6 & same \\
\hline Shower Water Consumption per Use & 45.4 & [Liter/use] & 12 & [ gal/use] \\
\hline Shower Use per Person per Day & 1 & [use/person/day)] & 1 & same \\
\hline Toilet Water Consumption per Use & 4.54 & [Liter/use] & 1.2 & [gal/use] \\
\hline Toilet Use per Person per Day & 5 & [use/person/day)] & 5 & same \\
\hline Kitchen Sink Water Consumption per Use & 1.9 & [Liter/use] & 0.5 & [gal/use] \\
\hline Kitchen Sink Use per Person per Day & 6 & [use/person/day)] & 6 & same \\
\hline Laundry Consumption per Use & 37.9 & [Liter/use] & 10 & [gal/use] \\
\hline Laundry loads per wash-day & 3 & [uses] & 3 & same \\
\hline Wash day of week logic integer & 0 or 1 & [once per week] & 0 or 1 & same \\
\hline Dishwasher Consumption per Use & 15.1 & [Liter/use] & 4 & [gal/use] \\
\hline Dishwashing day logic integer & 0 or 1 & [3x per week] & 0 or 1 & same \\
\hline $\begin{array}{l}t_{T E S} \text { season, start } \\
t_{T E S} \text { season, end }\end{array}$ & & $\begin{array}{c}\text { May } 1^{\text {st }} \\
\text { October } 1^{s}\end{array}$ & & \\
\hline
\end{tabular}

\subsection{Model outputs}

A table summary of the daily average on-peak and total daily cooling load, energy consumption, and maximum peak load for the reference case are shown in Table 3. These cooling load output is from the BEopt model, and the electricity consumption and power demand values are outputs of the hydronic system model (minus the thermal storage portions) discussed in Section 3.2.

The values in Table 3 provide context to the average daily energy flows (thermal and electrical) related to air conditioning for the house. Sizing the air conditioning system based on a criteria of meeting load $99 \%$ or more of the time yields a minimum system capacity of approximately 12,000 $\mathrm{BTU} / \mathrm{hr}$, or $3.5 \mathrm{~kW}_{\text {thermal }}$.

Figure 3 contains the $P L R_{\%}$, and Figure 4 contains the $E C C_{\%}$, for the tank size range and weather data specified in the previous subsection. The data output by the model are provided in Appendix B; Table B. 1 contains the $P L R_{\%}$ and $P L R_{k W}$, and Table B.2 contains the $E C C_{\%}$ and $E C C_{k W}$. Tank size analysis consisted of otherwise identical models iterating the tank water volume over the range of 378.5 to $3,785 \mathrm{~L}$ (100 to 1000 gallons) at increments of $378.5 \mathrm{~L}$ (100 gallons).

Figure 5 contains the $V_{\text {city }}, V_{\text {captured }}$, and $V_{\text {spilled }}$ for total rainwater storage volumes $\left(V_{\text {storage, } \max }=V_{\text {primary,max }}+V_{\text {storage } T E S}\right)$ ranging from (1,000 to 20,000 gallons) both with and without the (500 gallon) TES storage volume being actively utilized.

Figure 6 contains four plots of the rainwater storage level at each timestep $\left(V_{\text {storage }, t}\right)$ over the course of the analysis period (Jan. 1, 2011 through Dec. 31, 2013) for four total primary storage volumes levels. These plots show tank level for total storage tank capacities of 1,000 gal (3,785 L), 4,000 gal $(15,140 \mathrm{~L}), 7,000 \mathrm{gal}(26,495 \mathrm{~L})$, and 10,000 gallons (37,850 L), both with and without the TES being utilized. 
Table 3: The average daily cooling load, electricity consumption, and peak electricity demand were modeled using BEopt and the model described in Section 3.2

\begin{tabular}{|c|c|c|}
\hline & TMY3 & \\
\hline & Daily Total Average & Daily On-peak Average \\
\hline Total Cooling Load $k W h_{t h}(B T U)$ & $40.00(136,492)$ & $11.90(40,610)$ \\
\hline Max Cooling Load $k W h_{t h}(B T U / h r)$ & $2.84(9,704)$ & $2.84(9,704)$ \\
\hline Energy Consumed $(k W h)$ & 21.27 & 6.71 \\
\hline Max Electric Load Demand $(k W)$ & 2.53 & 2.53 \\
\hline & 2011 & \\
\hline Total Cooling Load $k W h_{t h}(B T U)$ & Daily Total Average & $\begin{array}{l}\text { Daily On-peak Average } \\
14.32(48,865)\end{array}$ \\
\hline Max Cooling Load kWh & $3.22(10,973)$ & $3.22(10,973)$ \\
\hline Energy Consumed $(k W h)$ & 28.02 & 8.73 \\
\hline Max Electric Load Demand $(k W)$ & 2.73 & 2.73 \\
\hline & 2012 & \\
\hline & Daily Total Average & Daily On-peak Average \\
\hline Total Cooling Load $k W h_{t h}(B T U)$ & $40.01(136,514)$ & $11.92(40,686)$ \\
\hline Max Cooling Load $k W h_{t h}(B T U / h r)$ & $2.84(9,699)$ & $2.84(9,699)$ \\
\hline Energy Consumed $(k W h)$ & 21.50 & 6.85 \\
\hline Max Electric Load Demand ( $k W$ ) & 2.59 & 2.59 \\
\hline & 2013 & \\
\hline & Daily Total Average & Daily On-peak Average \\
\hline Total Cooling Load $k W h_{t h}(B T U)$ & $44.51(151,862)$ & $13.03(44,467)$ \\
\hline Max Cooling Load $k W h_{t h}(B T U / h r)$ & $2.96(10,094)$ & $2.96(10,094)$ \\
\hline Energy Consumed ( $k W h)$ & 24.24 & 7.66 \\
\hline Max Electric Load Demand $(k W)$ & 2.64 & 2.64 \\
\hline
\end{tabular}

\section{Average Peak Load Reduction vs TES Volume for Summer Scenarios}

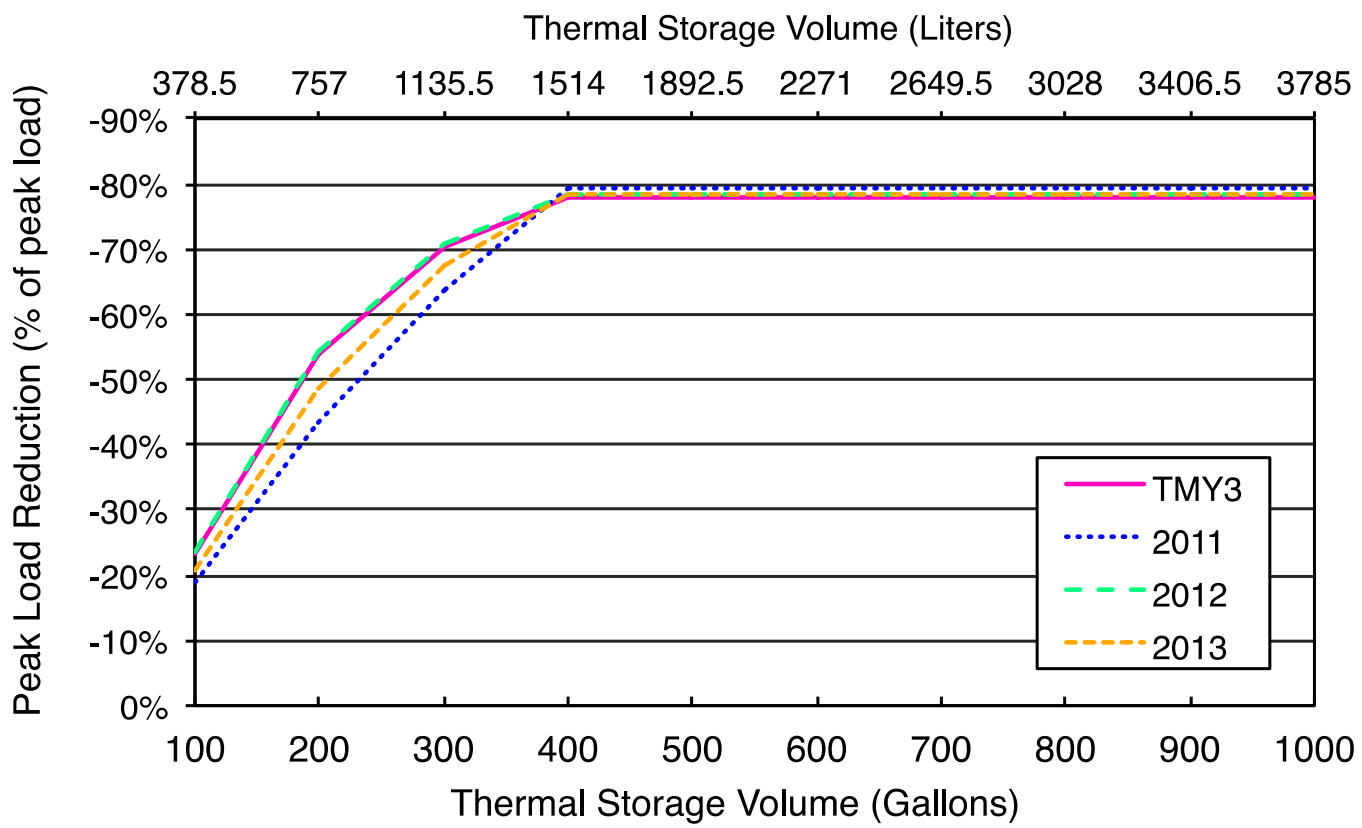

Figure 3: The model calculates peak load was reduced by the thermal storage, with a decrease in peak load for TES sizes up to approximately 400 gallons $(1500 \mathrm{~L})$, but that there is no additional decrease in peak load beyond that volume. 


\section{Average Energy Consumption vs TES Volume for Summer Scenarios}

Thermal Storage Volume (Liters)

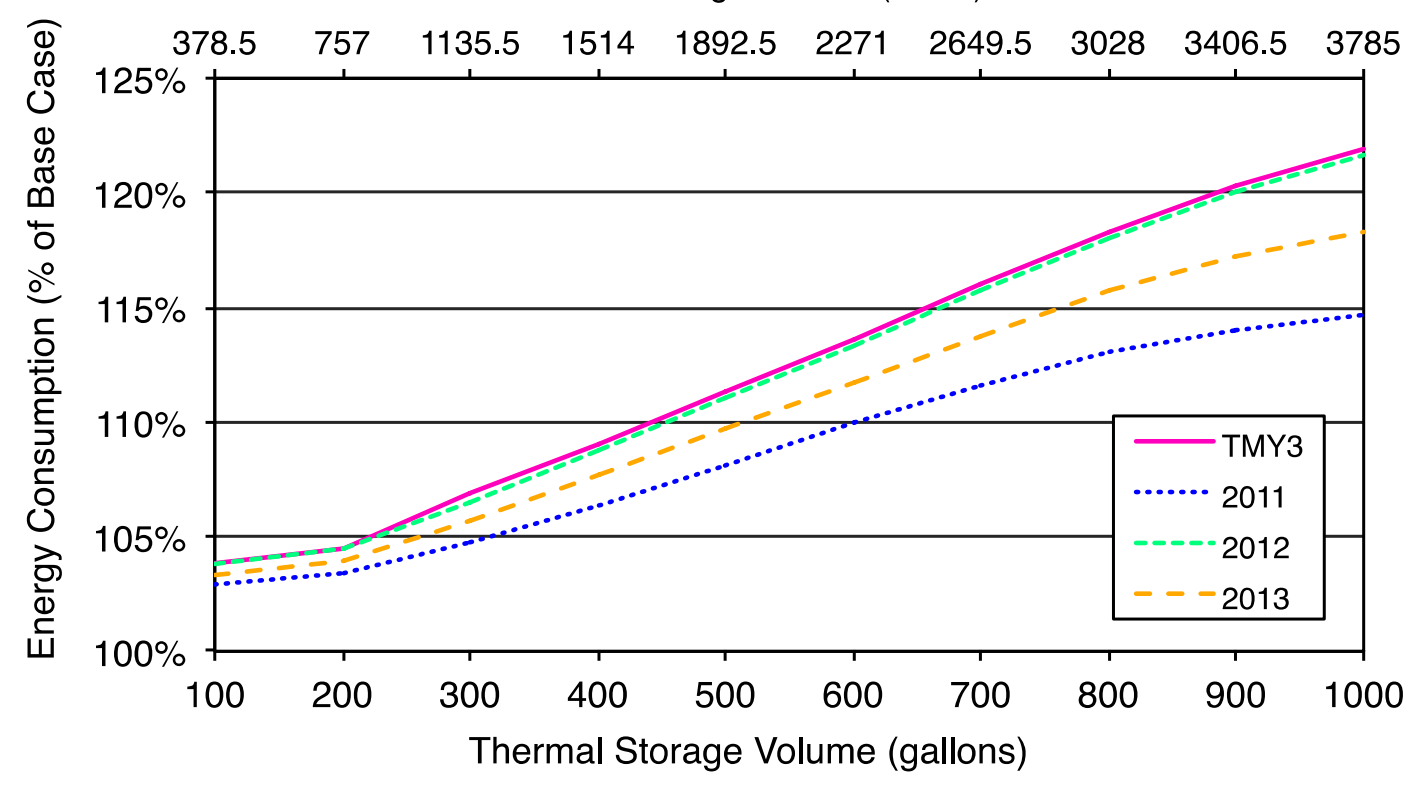

Figure 4: Total energy consumed by the system with and without thermal storage was calculated for 4 time periods over a range of tank sizes. The average energy consumed by the air conditioning system using the ITHERST system increased with increasing thermal storage size.

\section{Rainwater Captured and Spilled, and Municipal Water Bought, vs. Tank Size \\ for 2011-2013}

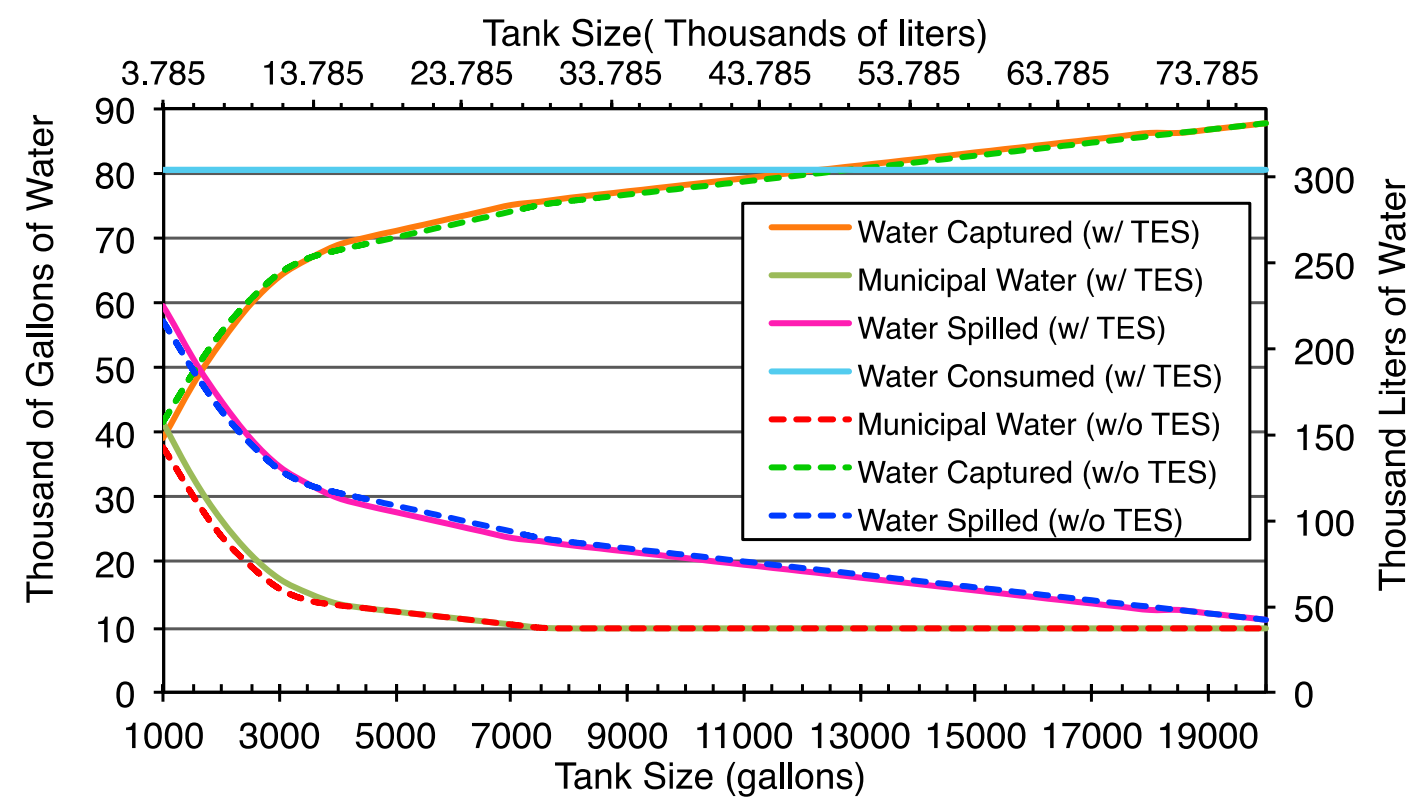

Figure 5: Rainwater captured increases and both rainwater spilled and municipal make-up water consumed decrease non-linearly with increasing storage tank size. This figure shows the impact of using a portion of the volume for thermal storage has little impact to no impact on the ability of the rainwater catchment system to reduce municipal water consumption. 


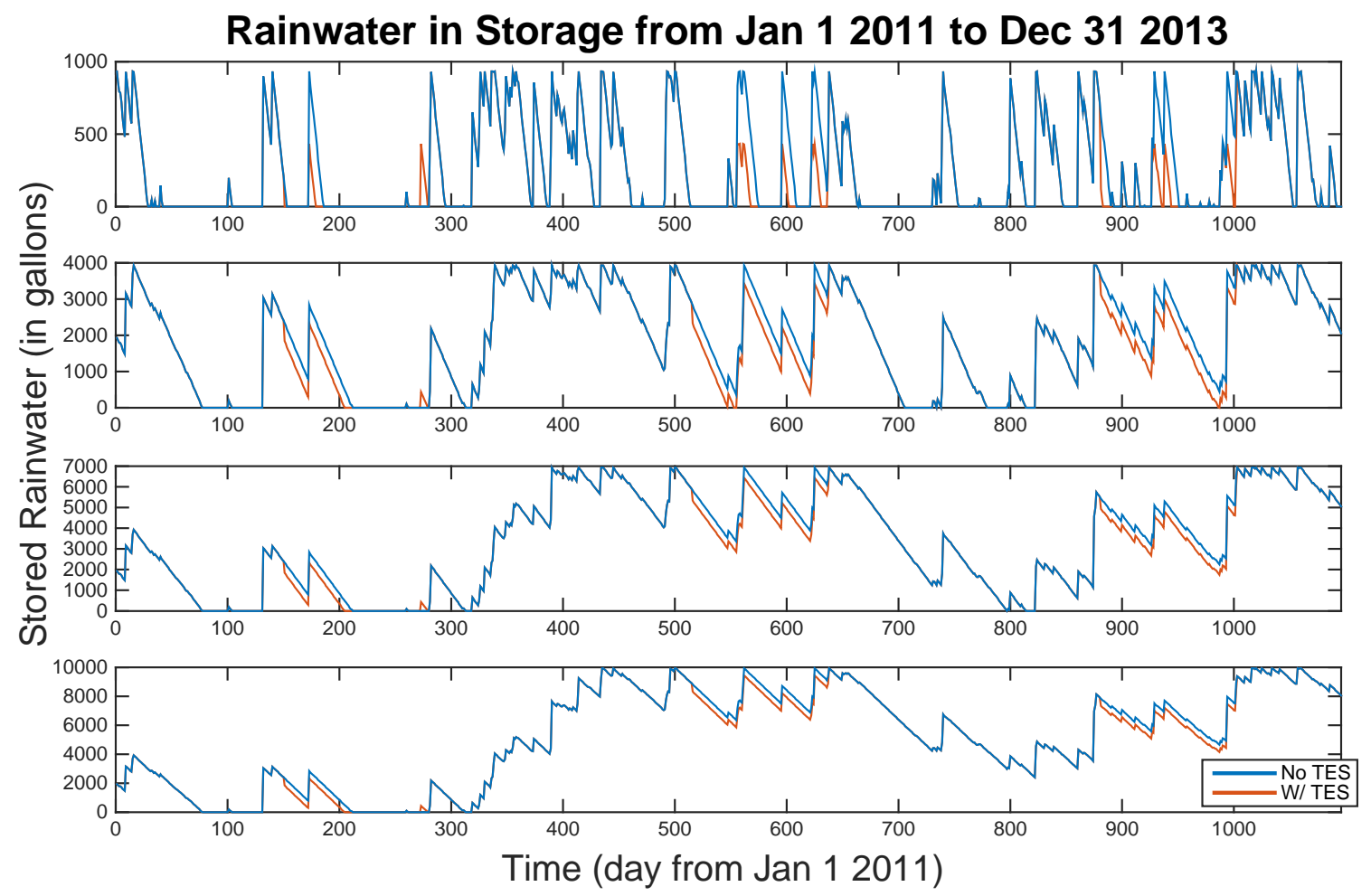

Figure 6: This series of four graphs show the water volume in the rainwater storage tank over the course of the analysis period. The maximum storage volume is (in descending graph order): 1000 gallons, 4000 gallons, 7000 gallons, and 10000 gallons. The red line is with a 500 gallon portion being seasonally utilized for TES, while for data for the blue line represents that volume remaining as available rainwater storage all year long. This figure shows that larger systems (greater than about 4000 gallons) do not suffer from the TES operation because the seasonal lost capacity does not lead to additional municipal consumption because there is still water available in the storage for consumption.

\section{$5 \quad$ ITHERST Results and Discussions}

Discussion of the model output for the thermal storage system performance presented in Section 4.2 are discussed in Section 5.1. The outputs of the rainwater collection system model from Section 4.2 are discussed and interpreted in Section 5.2.

\subsection{Thermal storage model analysis results and discussion}

Output from the BEopt model (shown in Table 3) estimated the house to require on average approximately $40-50 \mathrm{kWh}_{\text {thermal }}(136-170 \mathrm{kBTU})$ of cooling per day, and approximately 12-14 $\mathrm{kWh}_{\text {thermal }}$ (40-49kBTU) of that total cooling load occurs during the on-peak hours (2-8pm). The daily maximum hourly cooling demand is (on average) approximately $3 \mathrm{~kW}_{\text {thermal }}(10,200 \mathrm{BTU} / \mathrm{hr})$, and the corresponding average total electric power demand for the hydronic cooling system (chiller, pump, fan coils, etc.) approximately $2.6 \mathrm{~kW}$. Based on a design criteria of meeting load more than $99 \%$ of the time, the system size is approximately $3.5 \mathrm{~kW}_{\text {thermal }}(12,000 \mathrm{BTU} / \mathrm{hr}$ or 1 Ton of cooling). For comparison, an analysis approximately 5,000 energy audits from the Austin Energy Conservation and Disclosure ordinance found the average house air conditioner to have a rated capacity of approximately $11 \mathrm{~kW}_{\text {thermal }}(37,000 \mathrm{BTU} / \mathrm{hr}$ or 3.1 Tons of cooling) [66]. Dividing the rated capacity by the floor space of the house yields $13.3 \mathrm{~m}^{2} / \mathrm{kW}$ (505.6 $\mathrm{ft}^{2} /$ Ton) for the average Austin house; for comparison, the ratio is approximately $20.7 \mathrm{~m}^{2} / \mathrm{kW}$ (784 $\left.\mathrm{ft}^{2} / \mathrm{Ton}\right)$ for the house in this case study [6].

Comparing the modeled cooling load to that of a typical Austin house shows that the solar decathlon house used in this analysis represents a smaller and more thermally efficient design scenario. Therefore, extrapolating between the cooling load and peak load reduction of the ITHERST system 
model for Nexushaus and a typical Austin house should not be directly based on magnitude (e.g. kW), but rather a proportion of the reference case of each (e.g. \% reduction from the baseline). Additionally, validation of the Altherma ${ }^{\circledR}$ chiller cooling capacity model and electricity consumption is difficult due to lack of $3^{\text {rd }}$ party publicly available experimental data, but the curve fit output for cooling capacity and power demand matches that of the performance data provided by Daikin that were produced in accordance to European Standard EN 14511, so it is likely within at $15 \%$ of the rated performance $[56,57]$.

Since the absolute values are not experimentally validated (a topic of future work, discussed in the next section), evaluating performance on a relative scale provides a more reliable comparison because the self-normalization against a reference case cancels out some biases that might exist in the data underlying the empirical model. Therefore, $\mathrm{PLR}_{\%}$, and $\mathrm{ECC}_{\%}$ are the primary metrics used to evaluate the impact of the thermal storage system performance.

The PLR outputs from the analysis shown in Figure 3 depict a rapid increase in performance with increasing volume, and then a clear discontinuity in the 400-500 gallon (1514-1893 L) range. These results suggest that this ITHERST system, with the specified design parameters and over the specified periods, could reduce the on-peak cooling load (compared to the base case) by over $75 \%$. However, the peak load reduction does not increase any further for volumes beyond this point. The $P L R_{\%}$ and $P L R_{k W}$ data behind Figure 3 can be found in Table B.1 in the Appendix.

This sharp plateau is most likely due to the system reaching a minimum volume where it can draw all of the water it needs to meet the on-peak load, allowing the heat pump to stay off the whole time. At smaller volumes, the thermal storage could run out of capacity, and the heat pump might have to cycle on during the on-peak period to meet the unmet load. At larger volumes, the thermal storage simply cannot pump enough water to cycle through the entire tank during discharge or recharge, leaving an effectively unutilized volume of water in the tank.

Conversely, Figure 4 shows that the energy consumption change continues to steadily climb, with the ECC equal to approximately $7-9 \%$ for the tanks corresponding to the minimum volume to provide maximum PLR, but climbing past $20 \%$ in several cases at 1000 gallons (3785 L). Table B.2 contains the $E C C_{\%}$ and $E C C_{k W}$ model output data depicted in Figure 4. This increase in energy consumption is caused by cooling the TES until the entire tank temperature is back below the starting setpoint. This programming logic keeps the heat pump running to re-cool thermal mass, and in the larger volume tanks, there is a larger portion of water volume that doesn't contribute to the TES load shifting, but is slowly accumulating heat from the environment. While this model does not capture the details of natural convection and mixing within and between the tank strata (which might reduce the usable thermally stratified volume), this result does suggest that there could be a downside to choosing a TES tank significantly larger than the design load. More detailed modeling and experimental testing of the tank stratification will be a topic of future work.

When normalized to a volume per cooling capacity basis, the amount of water needed for effective thermal storage is on the order of approximately 120 gallons per Ton-hour (approximately $130 \mathrm{~L}$ per $\left.\mathrm{kWh}_{\text {thermal }}\right)$. These values are slightly higher, but of the same order of magnitude, as those cited for traditional large chilled thermal storage systems (typically around 100 gallons per Ton-hour) [33, 34]. A slightly higher volume/cooling capacity ratio can be attributed to a higher surface area to volume ratio, and a lower than typical supply/return differential than those used in larger systems. While developed from the specific parameters of this specific case study, this analysis confirms the general order of magnitude for the thermal storage volume and the order of magnitude for the peak load reduction, and can be used for approximating system size and peak load impact for other sized houses or small buildings. Dividing the total on-peak cooling delivered by the capacity of the air conditioning system yields a cooling capacity utilization of approximately 60-70\%. Multiplying this ratio to the system capacity of a 'typical' Austin house ( $11 \mathrm{~kW}_{\text {thermal }}$ or 3.1 Tons), summed over the 6 hour onpeak window leads total of $40-46 \mathrm{kWh}_{\text {thermal }}(11-13$ Ton-hours). Using the 120 gallons per Ton-hour sizing ratio, the corresponding thermal storage volume necessary to meet the load of a typical Austin 
house would be approximately 1300-1500 gallons (3900-4500 L). To the authors' knowledge, these approximate size and capacity estimates are not available in literature for chilled water systems for residential houses.

Based on these results, the following analysis of the rainwater collection system used a thermal storage volume of 500 gallons $(1893 \mathrm{~L})$ as a design input parameter, assuming this would provide an effective 400 gallons $(1514 \mathrm{~L})$ with which to perform thermal storage. This analysis shows that the volume of chilled water needed for shifting six hours of load (for this design case study) is significant but not unmanageably large, with 500 gallons being approximately $1 \mathrm{~m}$ in diameter and $2.4 \mathrm{~m}$ tall (39 in., and 96 in. respectively). These results have significant direct application to sizing the rainwater systems for the Nexushaus, as it is important to properly budget the portion of storage volume necessary seasonally set aside for thermal storage.

It is important to recognize that outputs are from only one specific model configuration, and that the performance and overall impact depend on the mode in which the system is operated. For instance, the TES on-peak discharging time period could be shortened or lengthened, the recharging time period could be similarly changed, and/or a host of other adjustments that could be made. Additionally, different efficiencies and power requirements for the auxiliary equipment will tested, as it can have a significant impact on the peak load reduction ratio and overall energy consumption [67]. This analysis was meant to demonstrate the general feasibility and provide a first-order estimation of performance. Future work will focus on iterating over various design and operating logic permutations to better determine the overall range of system sizing and thermal performance that could be expected. Additional future work will also integrate this model and the rainwater collection model with an overall economic analysis to ultimately determine the net economic value of these systems compared to homes without systems under different pricing scenarios.

\subsection{Auxiliary water collection and consumption model analysis results and discussion}

Figure 5 provides insight into the non-linear nature of rainwater collection at reducing dependence on an outside source such as municipally supplied water. The initial incremental impact of collecting and consuming rainwater is significant, as the additional volume is filled and emptied regularly. At the starting volume of 1000 gallons $(3785 \mathrm{~L})$, the system is effectively halving the household's consumption of city water by collecting enough rainwater to meet half of the demand over the threeyear span. As the system gets larger and larger however, the incremental increase in volume does not linearly correspond to a direct increase in water captured and avoided municipal consumption. Based on the time period analyzed with the stated house catchment area and water consumption parameters, this house would not be completely water independent on rainfall alone. This analysis shows that (for this scenario) approximately 8,000 or more gallons $(30283 \mathrm{~L})$ of storage would reduce municipal water consumption dependence to approximately $11 \%$ of total water consumption, and a 20,000 gallon $(75708 \mathrm{~L})$ system would provide the same municipal water savings benefit. This nonlinearity is because of the often sporadic and discrete nature of rain events in Texas (represented well by this historical dataset). Figure 6 visualizes the rainwater storage tank volume over the analysis period, and it demonstrates the feast or famine nature of rainfall in central Texas. The year 2011 was extremely dry (the first third of the graphs), with no measureable rainfall for months at a time, punctuated by a few rainfall events. During this span, all of the systems run dry and require municipal water backup, as there was just not enough rainfall onto the roof area to fill the systems that have available capacity. Following 2011, 2012 was a more consistent and historically representative year, with more frequent (and more intense) rainfall. During this span, systems greater than approximately 4,000 gallons (15142 L) provide all of water needed during the year.

Comparing between the graphs in Figure 6, the pattern observed is that as volume of storage increases, the frequency at which the system runs out of water or overflows decreases because the system can catch and hold more water during each rain event. As the storage becomes larger and larger, the catchment area (roof) becomes the limiting factor to how much water can be captured and effectively utilized. 
More broadly, this model demonstrates the importance of water efficiency measures, as the low consumption values are what allow such a small catchment area and tank volume to substantially support this household. Comparing to existing systems and analyses using numbers more typical of the average household, the system sizing much be approximately 2-3 times larger to meet all of the indoor consumption [10, 11, 68]. Additionally, this analysis shows that if significant water consumption reduction is the goal (rather than outright source replacement), even traditionally small volumes (e.g. $<5,000$ gallons or $18927 \mathrm{~L}$ ) can reduce the all of the outside supply necessary. This result has important implications for city and regional water system planners, especially in areas (such as Austin) with rapidly growing populations but constrained water resources.

Lastly, in Figures 5 and 6, the impact of using a portion of the volume for thermal storage has little to no impact on the ability of the rainwater catchment system to reduce municipal water consumption. At the smallest system sized analyzed (1000 gallons or $3785 \mathrm{~L})$, half of the system was used for thermal storage during the summer season. The fraction of city $\left(f_{\text {city }}\right)$ water consumed for the system without TES was 0.47 , while $f_{\text {city }}$ for the system utilizing the volume for TES was 0.51 ; at a system size of 4,000 gallons $f_{\text {city,No TES }}=0.161$ and $f_{\text {city,TES }}=0.163$. There is no difference beyond 5,000 gallons $(18927 \mathrm{~L})$ for this analysis.

The finding that integrating rainwater collection and thermal storage systems causes minimal-to-zero decrease in either systems performance-when systems are properly sized - is novel, and has not been previously explored or analyzed in prior research. This finding has important implications for further development of integrated systems, as it suggests that one potential technical downside (reduced performance) is not an issue if systems are correctly sized to meet their respective thermal and water demands.

Combined, these results suggest that these integrated systems have the technical potential to significantly reduce electric peak load demand and water consumption from residential houses. While the magnitude of the results from the case study analysis in this paper are not directly applicable to different sized houses or locations, the relative load reduction and water savings (approximately 75\% peak load reduction, approximately $90 \%$ municipal water savings) could be reasonably achieved on larger, more traditional, homes given proper system sizing and water efficiency measures.

These ITHERST systems could potentially significantly reduce the additional infrastructure needed to meet these new demands from growth in population and economic activity, and they could also potentially be retrofitted to existing houses as well for additional load reduction and water savings. Beyond Texas, there is significant potential utility of ITHERST systems. California has also had issues with growing population coupled with increasing energy demand and water scarcity; Australia has suffered from recent droughts and heat waves; and much of the developing world is increasingly electrified, and in need of air conditioning and clean water access. This analysis is the first step in exploring and quantifying the potential of these systems.

\section{Conclusions}

The purpose of this analysis was twofold: 1) provide a first approximation of the TES system performance of the described ITHERST system, 2) estimate the water savings for the rainwater collection system, and assess the impact of utilizing a portion of it for thermal storage.

This analysis consisted of calculating the peak load reduction $(P L R)$ and energy consumption change $(E C C)$ performance metrics using the described model for a range of tank sizes using the specified house parameters and historical weather data in Section 4. The analysis performed suggests that the proposed ITHERST system could reduce the on-peak cooling load (compared to the same system without TES) by over 75\%, when operating in Austin, Texas. Based on this limited analysis, there appears to be minimum tank volume needed to provide maximum peak load reduction (approximately $1500 \mathrm{~L}$ or 400 gallons). However, there does not appear to be any further benefits gained from having 
a tank significantly larger than the minimum. The ECC for the tank corresponding to the minimum volume is approximately 7-9\%. The energy penalty paid for the operation increases with tank size, and this is likely due to the increasing volume and overall magnitude of heat gain into the tank from the environment. These two observations lead to the preliminary conclusion that right-sizing the TES tank, rather than over-sizing, is advantageous from a TES performance standpoint.

The rainwater collection and consumption analysis showed that the system can reduce municipal water consumption significantly, but that it would not be able to reach full water independence if it were routinely facing low rainfall rates as those during 2011 in Texas. Maximum reduction in municipal water consumption was $89 \%$, and which was achieved by total storage volumes of 8,000 gallons $(30283 \mathrm{~L})$ and larger. In this analysis, there was no additional benefit to having systems larger than 8,000 gallons, however these systems did continue to accrue water even if it did not occur during the times needed to displace municipal use. The thermal storage operation had a minor impact on overall rainwater collection performance, increasing municipal consumption from $47 \%$ (no TES) to $51 \%$ (with TES) at the lowest system volumes level; at volumes of 5,000 gallons (18927 L) and higher, thermal storage operation had zero impact on the municipal water savings.

Combined, these results suggest that if the goal is to maximize overall system value while minimizing water consumption, then utilizing a portion of the rainwater system volume for thermal storage could be a worthwhile strategy.

\section{$7 \quad$ Future Work}

The actual economic value of this concept will ultimately govern its utility, and thus will be the focus on future work. The next step will be incorporating economic modeling with the peak load reduction and water savings models, taking into account capital and maintenance costs and the economic savings given various rate scenarios. Doing this economic analysis is not robust without a solid thermal/water model underpinning, and so using this ground-up model will allow for sensitivity analyses of system cost and value when various design parameters are changed.

The other major future work will be performing experimental testing of the major components of the system to validate (and/or determine) various real-world operating parameters. Specifically, testing will focus on the hydronic heat pump (chiller) to get a verified real-world performance, as well as testing a range of heat exchangers to better determine optimal design criteria and operating conditions.

Lastly, there will be a significant focus on testing many aspects of the thermal storage tank to improve the thermal modeling input parameters (insulation and heat transfer coefficients) and the internal stratification model, and using then this information to iterate on the tank design.

\section{Acknowledgement}

This work was made possible through funding provided by Pecan Street Inc. as part of the Pecan Street Smart Grid Demonstration Project Grant from the Department of Energy. The authors would also like to thank the UT/TUM Solar Decathlon Nexushaus team, the Universities, and the Department of Energy for the opportunity to design and test these ideas. Additional support was provided by the Texas State Energy Conservation Office to conduct analysis and initial prototyping of these concepts. A full list of sponsors of the UT/TUM Solar Decathlon Team is available here: http://www.nexushaus.com/support/sponsors/

A full list of sponsors for all projects in Dr. Webber's research group at UT are listed at http://www.webberenergygroup.com/about/sponsors. Dr. Webber's affiliations and board positions are listed at http://www.webberenergygroup.com/people/michael-webber.

In addition to research work on topics generally related to energy systems at the University of Texas at Austin, the authors are equity partners in IdeaSmiths LLC, which consults on topics in the same 
areas of interest. The terms of this arrangement have been reviewed and approved by the University of Texas at Austin in accordance with its policy on objectivity in research.

\section{Appendices}

\section{Appendix A Chiller Model Curve Fit and Coefficients}

This appendix contains a figure (Figure A.1) showing a plot of the cooling capacity and power demand empirical curve fits based on the data for a 1.5 ton Daikin Altherma split reversible hydronic heat pump [Cite Altherma], and reference its source. Additionally, included is a table with the corresponding coefficients for the curve fits.

\section{Cooling Capacity and Power Demand Datapoints and Curve Fits developed for Daikin Altherma Reversible Heat Pump}

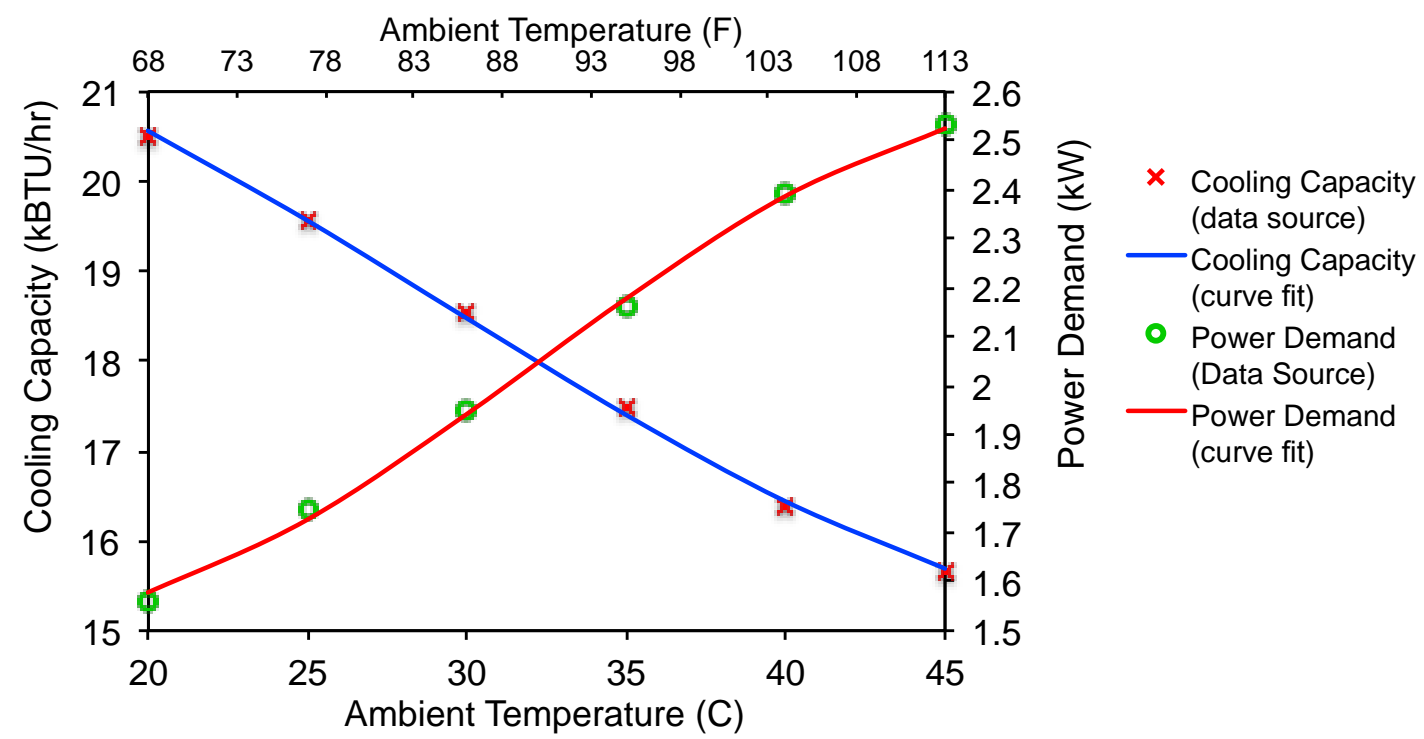

Figure A.1: The curve fits for cooling capacity and power demand from Equations 1 and 2 were plotted for a range of ambient temperature, using a supply water temperature of $45 F(7.2 C)$. There are points from the data source plotted for comparison.

Table A.1: The coefficients for Equations 1 and 2 are contained in the table below.

\begin{tabular}{|cllllllllllll|}
\hline \multicolumn{8}{c|}{ Daikin Altherma System Performance Empirical Curve Fit Coefficients } \\
Cooling & $a 1$ & $a 2$ & $a 3$ & $a 4$ & $a 5$ & $a 6$ & $a 7$ & $a 8$ & $a 9$ & $a 10$ \\
Capacity & 21.69 & -0.09691 & -0.1987 & 0.0129 & 0.04883 & -0.005659 & $-4.41 E-06$ & -0.0002747 & -0.000889 & 0.0001347 \\
& $b 1$ & $b 2$ & $b 3$ & $b 4$ & $b 5$ & $b 6$ & $b 7$ & $b 8$ & $b 9$ & $b 10$ \\
$\begin{array}{c}\text { Power } \\
\text { Demand }\end{array}$ & 3.495 & -0.1375 & -0.2147 & $-8.04 E-05$ & 0.0107 & 0.007132 & $1.63 E-06$ & $-9.21 E-06$ & -0.0001844 & $-6.06 E-05$ \\
\hline
\end{tabular}

\section{Appendix B Thermal Storage Analysis Data Tables}

This appendix contains two tables with the outputs from the TES analysis presented in Section 4 and discussed in Section 5. Table B.1 contains the relative and absolute Peak Load Reduction (PLR\% and $\mathrm{PLR}_{\mathrm{kW}}$ ) and Table B.2 contains the The relative and absolute Energy Consumption Change (ECC $\%$ and $\mathrm{ECC}_{\mathrm{kWh}}$ ) output from the analysis. 
Table B.1: The relative and absolute Peak Load Reduction (PLR\% and $\left.P L R_{k W}\right)$ were calculated using the ITHERST thermal model, and four distinct weather datasets, for a range of tank volumes.

\begin{tabular}{|c|c|c|c|c|c|c|c|c|}
\hline \multirow{3}{*}{$\begin{array}{c}\text { Tank Volume } \\
\text { (gallons) }\end{array}$} & \multicolumn{4}{|c|}{$P L R_{\%}$} & \multicolumn{4}{|c|}{$P L R_{k W}$} \\
\hline & & Weather & Dataset & & & Weathe & Dataset & \\
\hline & $T M Y 3$ & 2011 & 2012 & 2013 & $T M Y 3$ & 2011 & 2012 & 2013 \\
\hline 0 & - & - & - & - & 2.475 & 2.682 & 2.537 & 2.573 \\
\hline 100 & $-23.28 \%$ & $-18.87 \%$ & $-23.55 \%$ & $-20.72 \%$ & -0.565 & -0.504 & -0.594 & -0.531 \\
\hline 200 & $-54.01 \%$ & $-43.57 \%$ & $-54.49 \%$ & $-48.52 \%$ & -1.328 & -1.164 & -1.382 & -1.243 \\
\hline 300 & $-70.27 \%$ & $-63.77 \%$ & $-70.82 \%$ & $-67.35 \%$ & -1.733 & -1.707 & -1.796 & -1.729 \\
\hline 400 & $-77.69 \%$ & $-79.27 \%$ & $-78.24 \%$ & $-78.52 \%$ & -1.925 & -2.127 & -1.988 & -2.022 \\
\hline 500 & $-77.69 \%$ & $-79.44 \%$ & $-78.24 \%$ & $-78.52 \%$ & -1.925 & -2.132 & -1.988 & -2.022 \\
\hline 600 & $-77.69 \%$ & $-79.44 \%$ & $-78.24 \%$ & $-78.52 \%$ & -1.925 & -2.132 & -1.988 & -2.022 \\
\hline 700 & $-77.69 \%$ & $-79.44 \%$ & $-78.24 \%$ & $-78.52 \%$ & -1.925 & -2.132 & -1.988 & -2.022 \\
\hline 800 & $-77.69 \%$ & $-79.44 \%$ & $-78.24 \%$ & $-78.52 \%$ & -1.925 & -2.132 & -1.988 & -2.022 \\
\hline 900 & $-77.69 \%$ & $-79.44 \%$ & $-78.24 \%$ & $-78.52 \%$ & -1.925 & -2.132 & -1.988 & -2.022 \\
\hline 1000 & $-77.69 \%$ & $-79.44 \%$ & $-78.24 \%$ & $-78.52 \%$ & -1.925 & -2.132 & -1.988 & -2.022 \\
\hline
\end{tabular}

Table B.2: The relative and absolute Energy Consumption Change (ECC $C_{\%}$ and $\left.E C C_{k W h}\right)$ were calculated using the ITHERST thermal model, and four distinct weather datasets, for a range of tank volumes.

\begin{tabular}{|c|c|c|c|c|c|c|c|c|}
\hline \multirow{2}{*}{$\begin{array}{l}\text { Tank Volume } \\
\text { (gallons) }\end{array}$} & \multicolumn{4}{|c|}{$E C C_{\%}$} & \multicolumn{4}{|c|}{$E C C_{k W h}$} \\
\hline & $T M Y 3$ & 2011 & 2012 & 2013 & $T M Y 3$ & 2011 & 2012 & 2013 \\
\hline 0 & - & - & - & - & 2351.3 & 3101.9 & 2373.9 & 2679.9 \\
\hline 100 & $3.8 \%$ & $2.9 \%$ & $3.8 \%$ & $3.3 \%$ & 90.2 & 90.6 & 89.6 & 89.3 \\
\hline 200 & $4.5 \%$ & $3.4 \%$ & $4.4 \%$ & $3.9 \%$ & 105.0 & 104.5 & 105.0 & 105.2 \\
\hline 300 & $6.9 \%$ & $4.8 \%$ & $6.5 \%$ & $5.7 \%$ & 161.3 & 148.4 & 155.2 & 152.4 \\
\hline 400 & $9.1 \%$ & $6.3 \%$ & $8.8 \%$ & $7.7 \%$ & 213.3 & 195.7 & 207.6 & 204.9 \\
\hline 500 & $11.4 \%$ & $8.2 \%$ & $11.1 \%$ & $9.7 \%$ & 267.8 & 252.7 & 262.7 & 259.6 \\
\hline 600 & $13.7 \%$ & $10.0 \%$ & $13.4 \%$ & $11.8 \%$ & 321.5 & 309.1 & 317.8 & 315.4 \\
\hline 700 & $16.0 \%$ & $11.7 \%$ & $15.7 \%$ & $13.8 \%$ & 375.2 & 361.8 & 373.0 & 369.8 \\
\hline 800 & $18.3 \%$ & $13.1 \%$ & $18.0 \%$ & $15.8 \%$ & 429.8 & 405.9 & 426.9 & 422.1 \\
\hline 900 & $20.3 \%$ & $14.1 \%$ & $20.0 \%$ & $17.3 \%$ & 477.9 & 436.0 & 475.1 & 462.8 \\
\hline 1000 & $21.9 \%$ & $14.7 \%$ & $21.6 \%$ & $18.3 \%$ & 514.5 & 454.5 & 513.5 & 491.3 \\
\hline
\end{tabular}

\section{References}

[1] EIA. Monthly Energy Report, U.S. Energy Information Administration, February, 2015.

[2] M. A. Maupin, J. F. Kenny, S. S. Hutson, J. K. Lovelace, N. L. Barber, and K. S. Linsey. Estimated Use of Water in the United States in 2010, U.S. Geological Survey, November, 2014.

[3] Sanders, K. T., \& Webber, M. E. Evaluating the energy consumed for water use in the United States. Environmental Research Letters, 7(3), 034034, September 2012, doi:10.1088/17489326/7/3/034034

[4] Michael E. Webber. Thirst for Power: Energy, Water and Human Survival. Yale University Press, 2016.

[5] ERCOT. Report on the Capacity, Demand, and Reserves in the ERCOT Region - February 2014, Electric Reliability Council of Texas, February, 2014.

[6] Stillwell, A. S., King, C. W., Webber, M. E., Duncan, I. J., \& Hardberger, A. The EnergyWater Nexus in Texas. Ecology and Society, 16(1), 2011, Retrieved from http://www.ecologyandsociety.org/vol16/iss 1/art2/ 
[7] Cook, M. A., King, C. W., Davidson, F. T., \& Webber, M. E. Assessing the impacts of droughts and heat waves at thermoelectric power plants in the United States using integrated regression, thermodynamic, and climate models. Energy Reports, 1, 193-203, October 2015, doi:10.1016/j.egyr.2015.10.002

[8] Texas Water Development Board. 2012 Texas State Water Plan. Technical report, Texas Water Development Board, 2012.

[9] EIA. Residential Energy Consumption Survey (RECS) 2009: structural and geographic characteristics, U.S. Energy Information Administration, https://www.eia.gov/consumption/residential/data/2009/. Last Accessed Feb. 2016

[10] Texas Water Development Board. The Texas Manual on Rainwater Harvesting. Technical Report, Texas Water Development Board, 2005.

[11] Texas Water Development Board. Rainwater Harvesting Potential and Guidelines for Texas Report to the 80th Legislature. Technical Report November, State of Texas Rainwater Harvesting Evaluation Committee, 2006.

[12] The American Rainwater Catchment Systems Association, www.arcsa.org, Last Accessed: December, 2015.

[13] E. W. B. Boulware, (Et al). Rainwater Catchment Design and Installation Standards. The American Rainwater Catchment Systems Association, Revised 2013.

[14] R.M Roebuck and R.M Ashley. Predicting the hydraulic and life-cycle cost performance of rainwater harvesting systems using a computer based modelling tool. Water Practice \& Technology, 2(2), 2007.

[15] Khastagir, A., \& Jayasuriya, N. Optimal sizing of rain water tanks for domestic water conservation. Journal of Hydrology, 381(3-4), 181-188, November 2009, doi:10.1016/j.jhydrol.2009.11.040

[16] S. Ward, F. A. Memon, and D. Butler. Rainwater harvesting: model-based design evaluation. Water Science and Technology, 61(1):85-96, January 2010.

[17] Matthew P. Jones and William F. Hunt. Performance of rainwater harvesting systems in the southeastern United States. Resources, Conservation and Recycling 54:623-629, August 2010.

[18] Imteaz, M. A., Ahsan, A., Naser, J., \& Rahman, A. Reliability analysis of rainwater tanks in Melbourne using daily water balance model. Resources, Conservation and Recycling, 56(1), 80-86, September 2011, doi:10.1016/j.resconrec.2011.09.008

[19] James F. Sweeney and Michael Pate. Life cycle costs and field performance studies of a domestic rainwater harvesting application in a humid, sub-tropical, metropolitan environment. In Proc. World Environmental and Water Resource Congress 2015. ASCE, 2015.

[20] Okoye, C. O., Solyalı, O., \& Akıntuğ, B. Optimal sizing of storage tanks in domestic rainwater harvesting systems: A linear programming approach. Resources, Conservation and Recycling, 104, 131-140, August 2015, doi:10.1016/j.resconrec.2015.08.015

[21] Bocanegra-Martinez, A., Ponce-Ortega, J. M., Napoles-Rivera, F., Serna-Gonzalez, M., Castro-Montoya, A. J., \& El-Halwagi, M. M. Optimal design of rainwater collecting systems for domestic use into a residential development. Resources, Conservation and Recycling, 84, 44-56, January 2014, doi:10.1016/j.resconrec.2014.01.001

[22] Thomas, R. B., Kirisits, M. J., Lye, D. J., \& Kinney, K. A. Rainwater harvesting in the United States: A survey of common system practices. Journal of Cleaner Production, 75, 166-173, March 2014 doi:10.1016/j.jclepro.2014.03.073

[23] Sample, D. J., \& Liu, J. Optimizing rainwater harvesting systems for the dual purposes of water supply and runoff capture. Journal of Cleaner Production, 75, 174-194, March 2014, doi:10.1016/j.jclepro.2014.03.075 
[24] Malinowski, P. A., Stillwell, A. S., Wu, J. S., \& Schwarz, P. M. Energy-Water Nexus: Potential Energy Savings and Implications for Sustainable Integrated Water Management in Urban Areas from Rainwater Harvesting and Gray-Water Reuse. Journal of Water Resources Planning and Management, A4015003, 2015, doi:10.1061/(ASCE)WR.1943-5452.0000528

[25] Austin Energy. DSM Performance Measures, Fiscal Year 2010-2011 Final Report, Tech. rep., Austin Energy, 2011.

[26] Faruqui, A. Direct Load Control of Residential Air Conditioners in Texas. The Brattle Group, October 2012, Presentation for the Public Utility Commission of Texas.

[27] Cole, W. J., Rhodes, J. D., Gorman, W., Perez, K. X., Webber, M. E., \& Edgar, T. F. Community-scale residential air conditioning control for effective grid management. Applied Energy, 130, 428-436, June 2014, doi:10.1016/j.apenergy.2014.05.067

[28] Kensby, J., Trüschel, A., \& Dalenbäck, J. O. Potential of residential buildings as thermal energy storage in district heating systems - Results from a pilot test. Applied Energy, 137, 773-781, July 2014, doi:10.1016/j.apenergy.2014.07.026

[29] Turner, W. J. N., Walker, I. S., \& Roux, J. Peak load reductions: Electric load shifting with mechanical pre-cooling of residential buildings with low thermal mass. Energy, 82, 1057-1067, February 2015, doi:10.1016/j.energy.2015.02.011

[30] Doreen E. Kalz, Jan Wienold, Martin Fischer, and Davide Cali. Novel heating and cooling concept employing rainwater cisterns and thermo-active building systems for a residential building. Applied Energy, 87(2):650-660, February 2010.

[31] Park, S. H., Chung, W. J., Yeo, M. S., \& Kim, K. W. Evaluation of the thermal performance of a Thermally Activated Building System (TABS) according to the thermal load in a residential building. Energy and Buildings, 73, 69-82, January 2014, doi:10.1016/j.enbuild.2014.01.008

[32] Wang, L. S., \& Ma, P. The homeostasis solution - Mechanical homeostasis in architecturally homeostatic buildings. Applied Energy, 162, 183-196, October 2015, doi:10.1016/j.apenergy.2015.10.058

[33] I. Dincer, M. A. Rosen. Thermal Energy Storage: Systems and Applications, John Wiley \& Sons, Ltd., 2010.

[34] L. B. Hyman. Sustainable Thermal Storage Systems: Planning, Design, and Operations. McGraw-Hill, 2011.

[35] ASHRAE. 2009 ASHRAE Handbook - Fundamentals. ASHRAE, 2009.

[36] ASHRAE. ASHRAE Handbook: HVAC Systems and Equipment. ASHRAE, 2008.

[37] Bourne, S., \& Novoselac, A. PCM-based High-density Thermal Storage Systems for Residential and Small Commercial Retrofit Applications. Procedia Engineering, 121, 536-543, August 2015, doi:10.1016/j.proeng.2015.08.1025

[38] K. Roth, R. Zogg, and J. Brodrick. Cool Thermal Energy Storage. ASHRAE Journal, pages 94-96, September 2006.

[39] A. Arteconi, N. J. Newitt, and F. Polonara. State of the Art of Thermal Storage for DemandSide Management. Applied Energy, 93:371-389, January 2012.

[40] R. Willis and B. Parsonnet. Energy Efficient TES Designs for Commercial DX Systems. ASHRAE Transactions, 116:147-156, May 2010.

[41] Charles R Upshaw, Joshua D Rhodes, and Michael E Webber. Modeling A Combined Energy-Water Storage System For Residential Homes And Analyzing Water Storage Tank Size, In Proceedings ASME 2013 International Mechanical Engineering Congress and Expo. ASME, 2013.

[42] Upshaw, C. R., Rhodes, J. D., \& Webber, M. E. Modeling peak load reduction and energy consumption enabled by an integrated thermal energy and water storage system for residential air 
conditioning systems in Austin, Texas. Energy and Buildings, 97, 21-32, March 2015, doi:10.1016/j.enbuild.2015.03.050

[43] G. Gan, S. B. Riffat, and C. S. Chong. A novel rainwater-ground source heat pump measurement and simulation. Applied Thermal Engineering, 27(2-3):430-441, February, 2007.

[44] Ni, L., Lau, S. K., Li, H., Zhang, T., Stansbury, J. S., Shi, J., \& Neal, J. Feasibility study of a localized residential grey water energy-recovery system. Applied Thermal Engineering, 39, 53-62, January 2012, doi:10.1016/j.applthermaleng.2012.01.031

[45] Liu, X., Ni, L., Lau, S.-K., \& Li, H. Performance analysis of a multi-functional heat pump system in cooling mode. Applied Thermal Engineering, 59(1-2), 253-266, May 2013, doi:10.1016/j.applthermaleng.2013.05.032

[46] Kranz, S., \& Frick, S. Efficient cooling energy supply with aquifer thermal energy storages. Applied Energy, 109, 321-327, December 2012, doi:10.1016/j.apenergy.2012.12.002

[47] Gao, Y., Fan, R., Li, H., Liu, R., Lin, X., Guo, H., \& Gao, Y. Thermal performance improvement of a horizontal ground-coupled heat exchanger by rainwater harvest. Energy and Buildings, 110, 302-313, October 2015, doi:10.1016/j.enbuild.2015.10.030

[48] Novo, A. V., Bayon, J. R., Castro-Fresno, D., \& Rodriguez-Hernandez, J. Review of seasonal heat storage in large basins: Water tanks and gravel-water pits. Applied Energy, 87(2), 390-397, June 2009 doi:10.1016/j.apenergy.2009.06.033

[49] Nexushaus, www.nexushaus.com, The University of Texas at Austin, Last Accessed: December, 2015.

[50] The U.S. Dept. of Energy Solar Decathlon 2015 Competition, www.solardecathlon.gov, The U.S. Department of Energy, Last Accessed: December, 2015.

[51] BEopt v2.2, National Renewable Energy Laboratory, http://BEopt.nrel.gov, Last Accessed: February, 2015.

[52] EnergyPlus v8.1, Building Technologies Office, U.S. Department of Energy, http://apps1.eere.energy.gov/buildings/energyplus, Last Accessed: February, 2015.

[53] J. D. Rhodes, W. H. Gorman, C. R. Upshaw, M. E. Webber. Using BEopt (EnergyPlus) with energy audits and surveys to predict actual residential energy usage. Energy and Buildings 86: 808816, November, 2014.

[54] Daikin Altherma Hydronic Heat Pump, http://www.daikinac.com/content/residential/wholehouse/daikin-altherma, Last Accessed: December, 2015.

[55] Daikin Altherma Engineering Data, Daikin AC Inc. Daikin document reference number DACA-EEDEN11-720, April, 2011.

[56] Ware, D. W. Proposed Compliance Option for Altherma Air-To-Water Source Heat Pump for the Residential Energy Efficiency Standards. California Energy Commission,

2012,CEC-400-2011-010-SD

[57] CEN. European Standard for Air conditioners, liquid chilling packages and heat pumps with electrically driven compressors for space heating and cooling - Part 2: Test conditions. Brussels, 2007, EN 14511-2:2007: E

[58] AHRI. Standard for Performance Rating Of Water-Chilling and Heat Pump Water-Heating Packages Using the Vapor Compression Cycle. Air-Conditioning, Heating and Refrigeration Institute, 2011. AHRI Standard 550/590

[59] Peter W. Mayer, William B. DeOreo, et al. Residential end uses of water. American Water Works Research Foundation, 1999. ISBN 1-58321-016-4

[60] William B. DeOreo, Peter W. Mayer, et al. California Single-Family Water Use Efficiency Study. Sponsored by the California Department of Water Resources, 2011. 
[61] Charles R Upshaw, Joshua D Rhodes, and Michael E Webber. Estimating water savings from an auxiliary water collection system, as part of an integrated thermal energy and water storage system for residential buildings. In Proc. ASHRAE 2015 Winter Conference. ASHRAE, 2015.

[62] NREL tmy3 database, http://rredc.nrel.gov/solar/old data/nsrdb/1991-2005/tmy3/by state and city.html, Last Accessed: December, 2015.

[63] Weather analytics weather data. http://www.weatheranalytics.com/wa/products/data-weatherfiles, Last Accessed: December, 2015.

[64] Austin Energy Rate Schedule, https://rates.austinenergy.com, Last Accessed: December, 2015.

[65] U.S. Department of Energy Solar Decathlon Building Code. U.S. Department of Energy National Renewable Energy Laboratory. Last Updated September 24, 2014.

[66] Rhodes, J. D., Stephens, B., \& Webber, M. E. Using energy audits to investigate the impacts of common air-conditioning design and installation issues on peak power demand and energy consumption in Austin, Texas. Energy and Buildings, 43(11), 3271-3278, August 2011, doi:10.1016/j.enbuild.2011.08.032

[67] Kalz, D. E., Herkel, S., \& Wagner, A. The impact of auxiliary energy on the efficiency of the heating and cooling system: Monitoring of low-energy buildings. Energy and Buildings, 41(10), 1019-1030, May 2009, doi:10.1016/j.enbuild.2009.05.004

[68] Venhuizen, D., Ford, K., Miller, M., Bray, S., Payne, S., \& Sansom, A. Rainwater Harvesting as a Development-Wide Water Supply Strategy Final Report. Submitted to the Texas Water Development Board, October 2013. 